\title{
Role of HDACs in normal and malignant hematopoiesis
}

\author{
Pan Wang ${ }^{1,2}$, Zi Wang ${ }^{1,2^{*}}$ and Jing Liu ${ }^{2^{*}}$
}

\begin{abstract}
Normal hematopoiesis requires the accurate orchestration of lineage-specific patterns of gene expression at each stage of development, and epigenetic regulators play a vital role. Disordered epigenetic regulation has emerged as a key mechanism contributing to hematological malignancies. Histone deacetylases (HDACs) are a series of key transcriptional cofactors that regulate gene expression by deacetylation of lysine residues on histone and nonhistone proteins. In normal hematopoiesis, HDACs are widely involved in the development of various lineages. Their functions involve stemness maintenance, lineage commitment determination, cell differentiation and proliferation, etc. Deregulation of HDACs by abnormal expression or activity and oncogenic HDAC-containing transcriptional complexes are involved in hematological malignancies. Currently, HDAC family members are attractive targets for drug design, and a variety of HDAC-based combination strategies have been developed for the treatment of hematological malignancies. Drug resistance and limited therapeutic efficacy are key issues that hinder the clinical applications of HDAC inhibitors (HDACis). In this review, we summarize the current knowledge of how HDACs and HDAC-containing complexes function in normal hematopoiesis and highlight the etiology of HDACs in hematological malignancies. Moreover, the implication and drug resistance of HDACis are also discussed. This review presents an overview of the physiology and pathology of HDACs in the blood system.
\end{abstract}

Keywords: Histone deacetylases, Hematopoiesis, Hematological malignancy, HDAC inhibitor, Drug resistance

\section{Introduction}

Epigenetic modifications play an indispensable role in the expression of hematopoietic lineage-specific genes. HDAC (histone deacetylase) and HAT (histone acetyltransferase) are two opposite classes of epigenetic modification enzymes. Generally, acetylation mediated by HATs opens the chromatin and allows gene transcription, whereas HDACs have a repressive effect on gene expression by deacetylating lysine residues on histone tails [1, 2]. Mammalian HDACs consist of 18 highly conserved genes [3], and they are divided into Class I (HDAC1, HDAC2, HDAC3, HDAC8), Class IIa (HDAC4, HDAC5, HDAC7, HDAC9), Class IIb (HDAC 6, HDAC 10), Class III (sirt1-sirt7) and Class IV (HDAC11) on the basis of phylogenetic analysis and sequence similarity to yeast factors (Fig. 1) [4]. Class I members are ubiquitously expressed with predominant

\footnotetext{
* Correspondence: zhongnanwangzi@126.com; jingliucsu@hotmail.com ${ }^{1}$ The Xiangya Hospital, Central South University, Changsha 410005, Hunan, China ${ }^{2}$ Molecular Biology Research Center and Hunan Province Key Laboratory of Basic and Applied Hematology, School of Life Sciences, Central South University, Changsha 410078, Hunan, China
}

nuclear localization $[5,6]$. Furthermore, they are composed of approximately 400 amino acids and contain an $\mathrm{N}$-terminal catalytic domain. Their catalytic domain is similar to a pocket and consists of two adjacent histidine residues, two aspartic acid residues and one tyrosine residue with $\mathrm{Zn}^{2+}$ ions as the core [7]. Class II members are more selectively expressed and can shuttle actively between the nucleus and cytoplasm $[5,6]$. There are 600-1200 amino acids with an N-terminal regulatory domain that mediates the interaction with tissue-specific transcription factors and corepressors in class IIa HDACs. Importantly, there are two or three conserved serine residues in the class IIa $\mathrm{N}$-terminal domain that can be phosphorylated by kinases, such as protein kinase $\mathrm{D}$ (PKD), which determines the nuclear export of class IIa HDACs $[8,9]$. Class IIb members HDAC6 and HDAC10 contain another catalytic domain and an ubiquitin-binding zinc finger domain at the C-terminal region, respectively $[7,8]$. The sirtuin family (SIRT1-7) of deacetylases represents class III, but they are functionally unrelated to HDACs; their deacetylase activity

(c) The Author(s). 2020 Open Access This article is distributed under the terms of the Creative Commons Attribution 4.0 International License (http://creativecommons.org/licenses/by/4.0/), which permits unrestricted use, distribution, and 


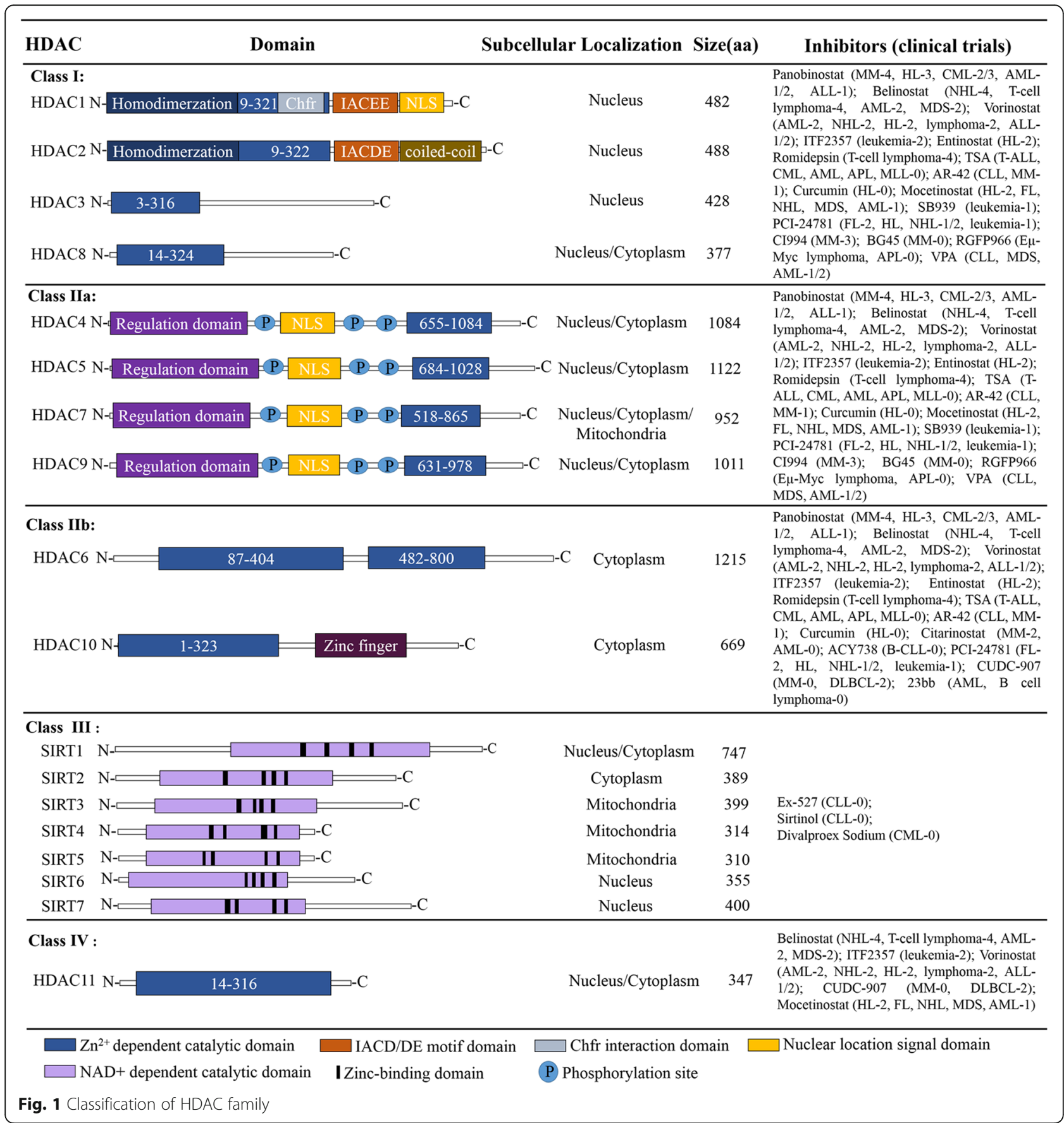

depends on $\mathrm{NAD}^{+}$rather than on $\mathrm{Zn}^{2+}$-dependent enzymes [7]. As the smallest member of the HDAC family, HDAC11 is predominantly located in the nucleus, and more than $80 \%$ of the amino acid sequence is assigned to its catalytic domain [10].

As a series of epigenetic regulatory molecules, HDACs are involved in multiple aspects of hematopoiesis, such as stemness maintenance and lineage commitment. Abnormal expression or activity of HDACs and abnormal interactions between HDACs and transcription factors
(TFs)/cofactors interfere with downstream gene regulatory networks, culminating in many different types of malignant hematopoietic diseases, such as lymphoma and leukemia [11]. Currently, HDAC inhibitors (HDACis) have been widely used as single agents or in combination with other chemotherapeutics in tumor treatment. However, therapy resistance remains a key problem. In this review, we focus on recent findings on the role of HDACs and their complexes in regulating gene expression during hematopoiesis or hematological 
malignancies, followed by a summary of combination therapy strategies and resistance mechanisms of hematological malignancies to HDACis.

\section{HDACs in hematopoiesis}

HDACs are extensively involved in multilineage development, including the hematopoietic stem cell (HSC)-progenitor lineage, granulocyte-monocyte lineage, erythropoietic lineage and lymphoid lineage (Fig. 2). During hematopoiesis, HDACs participate in the formation of a variety of transcriptional complexes where the reciprocal regulation between HDACs and TFs or other cofactors regulate histone acetylation levels, TF activity and functions of transcriptional complexes, which in turn modulate expression of various hematopoietic-related genes [12-17] (Table 1).

\section{HSCs and progenitor lineage differentiation}

HDAC1 and HDAC2 are essential regulators of HSC formation and homeostasis. Simultaneous deletion of HDAC1 and HDAC2 results in the loss of HSCs and, consequently, early hematopoietic progenitors, which are associated with the deregulated expression of genes linked to stem cell survival and maintenance, such as Dmkn, Nurcks1 and Tpt1 [18]. HDAC1 exhibits dynamic expression changes in cell lineage specification during hematopoiesis. Its expression is relatively low in human and mouse CD34+ hematopoietic progenitor cells (HPCs) and mature myeloid cells (monocytes and granulocytes). HDAC1 transcripts are moderately expressed in committed progenitors, erythroblasts and peripheral blood $\mathrm{T}$ lymphocytes. The unique expression pattern of HDAC1 is subject to regulation by hematopoietic transcription factors. For instance, HDAC1 transcription is repressed by GATA2 and C/ EBP during common myeloid progenitor (CMP) differentiation into myeloid cells, especially granulocytes, and is activated by GATA1 and Sp1 during CMP differentiation into erythro-megakaryocytic cells $[19,20]$. Specifically, knockdown of HDAC1 promotes hematopoietic progenitor differentiation toward the myeloid lineage with an increase in granulocyte/macrophage colonies and a reduction in the numbers and sizes of CFU-E and BFU-E, suggesting a role for HDAC1 in lineage commitment determination [6].

Class I HDAC3 was identified as a negative regulator in normal human HSC expansion. In vitro, HDAC3 silencing by HDACi-VA promoted CD34+ cell expansion without affecting differentiation potential [21]. Conditional deletion of HDAC3 in mice increased stem cells and early progenitor cells and blocked progress toward lymphoid-primed multipotential progenitor (LMPP) cells and lymphoid lineages, in which the loss of HDAC3 could impair $\mathrm{S}$ phase progression of multipotential progenitor (MPP) cells and, in turn, hinder cell DNA replication [22]. HDAC3 regulates the development of HSCs by interacting with HSC or HPC-specific TFs. For

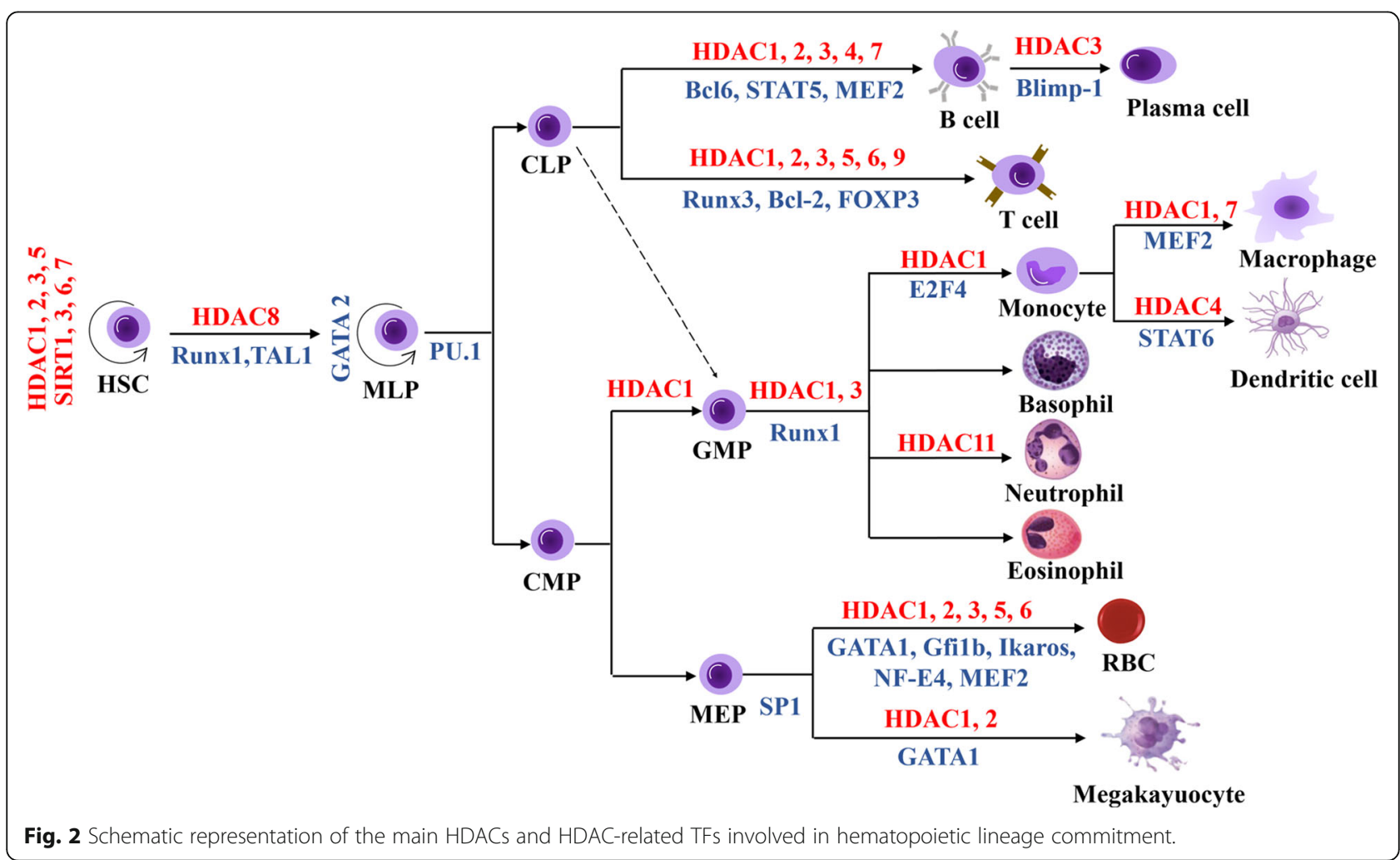


Table 1 HDAC-TF complexes in normal and malignant hematopoietic cells and their functions

\begin{tabular}{|c|c|c|c|}
\hline TF(s) & Complex components & Cell type or disease & Function \\
\hline \multirow[t]{4}{*}{ GATA1 } & GATA1-acHDAC1 & MEL cells & Promoting $\beta$-globin expression and erythroid commitment \\
\hline & GATA1-HDAC3/HDAC4/HDAC5 & cos cells & May repress GATA1 target genes and inhibit erythroid cell differentiation \\
\hline & pERK-HDAC5-GATA1-EKLF & Human erythroblast & Inhibiting the transcription of globin genes \\
\hline & GATA-1-SCI/TAL1-ET02-HDACs & G1E-ER-GATA1 cells & Participating in chromosomal translocation in AML \\
\hline GATA2 & GATA2-HDAC3/HDAC5 & cos cells & Repressing the transcriptional activity of GATA2 \\
\hline GATA3 & GATA3-Tbet-HDAC3/HDAC5 & Jurkat cells & Regulating lymphocyte homing \\
\hline EKLF & EKLF-HDAC $1 / \operatorname{Sin} 3 \mathrm{~A}$ & K562 cells & Inhibiting $\beta$-globin gene expression \\
\hline \multirow[t]{2}{*}{ PU.1 } & PU.1-HDAC1/Sin3A & MEL cells & Inhibiting $\beta$-globin gene expression \\
\hline & PU.1-Eto2- Sin3A-HDAC2 & AML cells & Inhibiting myeloid differentiation genes, such as Mcsfr and Gmcsfr \\
\hline Ikaros & Ikaros-GATA1-FOG1-HDAC1/NuRD & Mouse erythroid cells & Inhibiting $\gamma$-globin gene expression \\
\hline \multirow[t]{2}{*}{ Gfi } & Gfi-1-G9a-HDAC1 & HL60 cells & Repressing the expression of p21Cip/WAF1 \\
\hline & Gfi1b-CoREST-LSD1-HDAC 1/2 & MEL cells & Committing hematopoietic differentiation \\
\hline GFI1B & GFI1B-LSD1-RCOR1-HDAC1/2 & Megakaryoblasts & Controlling megakaryoblast proliferation and differentiation \\
\hline NF-E4 & NF-E4 - HDAC1 & K562 cells & 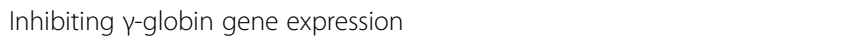 \\
\hline E2F4 & E2F4-RBL2-HDAC1-BRM (SWI/SNF) & Human monocytes & Repressing pluripotency stem cell factors in human monocytes \\
\hline \multirow[t]{2}{*}{ Runx1 } & Runx1-HDAC1/HDAC3 & Human macrophages & Negatively regulating granulocyte formation \\
\hline & Runx1-Eto2-Sin3A-HDAC2 & AML cells & Inhibiting myeloid differentiation genes, such as Mcsfr and Gmcsfr \\
\hline \multirow[t]{2}{*}{ RUNX1/T1 } & RUNX1/RUNX1T1-HDACs-DNMTs & $\mathrm{t}(8 ; 21) \mathrm{AML}$ cells & Inducing leukemogenesis \\
\hline & RUNX1/RUNX1T1-ETO-Sin3A-HDAC2 & AML cells & Causing aberrant repression of late differentiation genes \\
\hline \multirow[t]{3}{*}{ MEF2 } & MEF2A/D-HDAC1/HDAC7 & Human macrophages & Repressing the transcription of c-Jun \\
\hline & MEF2-HDAC9 & K562 cells & Activating $\mathrm{\gamma}$-globin gene a and inducing $\mathrm{HbF}$ synthesis \\
\hline & MEF2C-HDAC7 & Human lymphoma & Silencing lineage-inappropriate genes in pro-B cells \\
\hline TCF/LEF1 & TCF/LEF1-SIRT6 & Mouse stem cells & Inhibiting Wnt target genes and maintaining HSC homeostasis \\
\hline Blimp-1 & HDAC1/HDAC2 & pre-B cells & Inhibiting c-myc transcription \\
\hline STAT5 & HDAC3-LSD1-STAT5 & pro-B cells & Promoting the maturation of B cells \\
\hline Bach2 & Bach2-HDAC3-NCoR1/NCoR2-Rif1 & Mature B cells & Increasing the deacetylation of Blimp-1 gene \\
\hline \multirow[t]{3}{*}{ BCL6 } & BCL6/SMRT-HDAC3 & Human DLBCL cells & Establishing GC responses \\
\hline & BCL6-HDAC4 & Spleen B cells & Blocking B cell development and inducing uncontrolled cell proliferation \\
\hline & BCL6-HDAC9 & Mouse B-NHL cells & Deacetylating BCL6 and upregulating proliferation and survival genes \\
\hline NF-KB & Sirt1-p300- NF-kB & Mouse T cells & Inhibiting transcription of Bclaf1 \\
\hline \multirow[t]{5}{*}{ AML1 } & AML1-ETO-NCoR-mSin3-HDACs $(1,2,3)$ & $\mathrm{t}(8 ; 21)$ AML cells & Repressing AML1-mediated transactivation and activating leukemogenesis \\
\hline & AML1-ETO-HDAC1/NCOR-SMRT & $\mathrm{t}(8 ; 21) \mathrm{AML}$ cells & Repressing AML1-mediated transactivation and activating leukemogenesis \\
\hline & AML1-MTG16-HDAC1/3 & $\mathrm{t}(16 ; 21) \mathrm{AML}$ cells & Participating in nucleolar targeting \\
\hline & TEL-AML1-HDACs & $\mathrm{t}(12 ; 21)$ ALL cells & Repressing AML1 target genes \\
\hline & AML1-MDS1-EVI1-CtBP1-HDAC1 & MDS/CML/AM cells & Repressing gene transcription and inducing leukemia in mice \\
\hline PML & PML-RARa-NCoR-Sin3-Ski/Sno-HDACs & $\mathrm{t}(15 ; 17)$ APL cells & Inhibiting Rb and TRß-mediated silencing and inducing leukemogenesis \\
\hline PLZF & RARa-PLZF-HDAC1/NCoR-Sin3 & $\mathrm{t}(11 ; 17)$ APL cells & Impairing C/EBPa function and contributing to differentiation arrest in APL \\
\hline
\end{tabular}

example, HDAC3 cooperates with Ncor2 to repress the fos-vegfd cascade by modulating the acetylation level in the fos promoter region, thereby mediating HSC formation [23]. HDAC3 directly interacts with GATA2 to inhibit GATA2-dependent targeting genes, which may be achieved by modifying the acetylation status of GATA2 in HPCs [24]. Another class I member HDAC8 is highly expressed in LT-HSCs, MPP and LMPP cells. HDAC8 plays a pivotal role in the maintenance and functional integrity of LT-HSC by deacetylating p53 [25].

Some class II and class III HDAC members are also involved in HSC homeostasis and aging. Class IIa HDAC5 has been shown to negatively regulate HSC homing by regulating p65 deacetylation [26]. Class III 
(SIRT1-SIRT7) members have been implicated in protecting HSCs from aging [27]' Specifically, SIRT1 maintains aged HSC homeostasis by promoting nuclear localization and activation of FOXO3 and negatively regulating mTOR signaling [27-29]. Downregulation of SIRT3 in stem cells is associated with the aging of HSCs by regulating the global acetylation landscape of mitochondrial proteins and increasing ROS. While upregulation of SIRT3 can rescue functional defects in aged HSCs [30]. SIRT6 maintains HSC homeostasis by interacting with TCF/LEF1 and inhibiting the transcription of Wnt target genes via deacetylating H3K56ac [31]. SIRT7 maintains aged HSCs and prevents myeloid differentiation by repressing NRF1 (a key regulator of mitochondrial genes) and PFSmt (a mitochondrial protein folding stress factor) [32]. In addition, SIRT1 plays a critical role in promoting the mutation acquisition of CML, an age-dependent malignancy. Inhibition of SIRT1 sensitizes leukemic stem cells to imatinib treatment and blocks the acquisition of resistant BCR-ABL mutations by altering the function of DNA repair machineries in CML cells, and reduces the error-prone repair activity of DNA damage [33]. Further understanding of sirtuins in HSC aging and malignancy may provide novel treatment strategies to deter hematological aging and improve the treatment of hematological malignancies.

\section{Granulocyte-monocyte lineage terminal differentiation}

In the bone marrow, granulocyte-monocyte terminal differentiation generally arises from upstream granulocytemonocyte progenitors (GMPs), which have the potential to differentiate into granulocytes, dendritic cells (DCs) and monocytes/macrophages (Fig. 2) [34-36]. Class I and II HDACs are crucial for the proliferation and differentiation of bone marrow-derived monocytes (BMDMs) into macrophages and DC cells. For instance, under the treatment of TSA (a class I and II HDAC inhibitor), the amplification of murine myeloid progenitors is blocked and, in turn, differentiate into an elongated morphology of mixed M1/M2 profile, instead of the normal pancake-like shape of M1 inflammatory macrophages [37]. In addition, TFs associated with HDAC complexes shows dynamic changes during premonocyte to monocyte differentiation. For example, the differentiation-associated cell cycle exit induces E2F1 replacement with E2F4 at the PARP1 promoter and the assembly of an E2F4-RBL2-HDAC1-BRM (SWI/SNF) repressor complex which reduces PARP1 transcription and represses of pluripotent transcription factors such as POU5F1, SOX2, and NANOG [38]. Moreover, HDAC1 and HDAC7 have been implicated in macrophage terminal differentiation. Both of them interact with MEF2A/D heterodimers on the c-Jun promoter, thereby repressing the transcription of c-Jun, which is important for the development of the monocyte/macrophage lineage [39]. HDAC1 and HDAC3 are implicated in granulopoiesis. When Runx1 is phosphorylated by Src kinase, the reduced interaction of Runx1-HDAC1/HDAC3 is relevant to increased DNA affinity and the induction of granulopoiesis [40]. Class IIa HDAC4 can be recruited to the Arg1 promoter region, which leads to a reduction in the acetylation of both histone 3 and STAT6 proteins and subsequent transcriptional activation of Arg1, resulting in monocyte and $\mathrm{CD} 8 \alpha(+)$ conventional DC differentiation [41]. Importantly, in some case, the aberrant recruitment of HDAC complexes by the oncofusion TFs to key hematopoietic genes is critical for leukemic transformation. For instance, in AML, AML1ETO and RARalpha-PLZF fusions recruit NCoR/SMRTHDAC1/3, while lose their binding ability with P300/ $\mathrm{MOZ} / \mathrm{pCAF} / \mathrm{CoA}$ present at normal cells, thus reducing histone acetylation and producing repressive chromatin organization by HDACs, which results in gene transcriptional repression responsible for hematopoietic differentiation and, potentially, activation of a subset of other genes, including those for macrophage colony-stimulating factor and BCL-2 [42] (Fig. 3).

HDACs are able to regulate the transcription of granulocyte-macrophage colony-stimulating factor (MCSFR), granulocyte colony-stimulating factor (GMCSFR) and cytokines to control the development and activation of granulocyte-monocyte cells [34-36]. For instance, Runx1 and PU.1 independently interact with the ETO2-SIN3A-HDAC2 corepressor complex coactivate MCSFR and GMCSFR expression [43]. Additionally, class IV HDAC11 is gradually increased from promyelocytes to neutrophils differentiation. Knockout of HDAC11 in mice showed the expansion of maturing neutrophils and increases in TNF- $\alpha$ and IL-6 [2]. Importantly, several studies have shown that cytokines, including IL-2, IL-12, TNF- $\alpha$ and GM-CSF, regulate the innate and adaptive immune system and enhance immunity against FL, NHL and CLL [44]. The involvement of HDACs in cytokines transcription regulation in neutrophils propose a combination application of HDACis and cytokines, which potentially contributes to an enhanced tumor immuneresponse.

\section{Erythrocyte lineage terminal differentiation}

Terminal erythroid differentiation begins with proerythroblasts, which subsequently undergo sequential mitoses, transforming into basophilic, polychromatic, and orthochromatic erythroblasts and enucleating into reticulocytes [45] (Fig. 2). The distinct interaction pattern between HDACs and erythroid-specific TFs plays an important regulatory role in erythropoiesis. HDAC1 and/or HDAC2 are the basic components of the SIN3A, $\mathrm{NuRD}$ and CoREST corepressor complexes [46, 47]. HDAC1/Sin3A can be recruited by EKLF to inhibit $\beta$ globin expression in undifferentiated EBHX11L cells, 


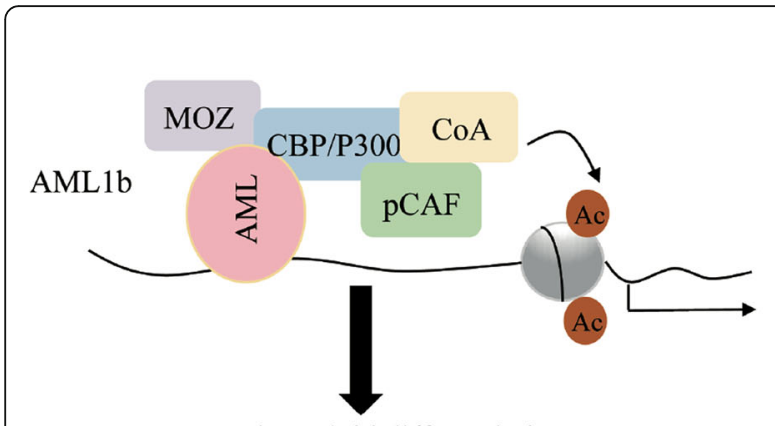

Normal myeloid differentiation

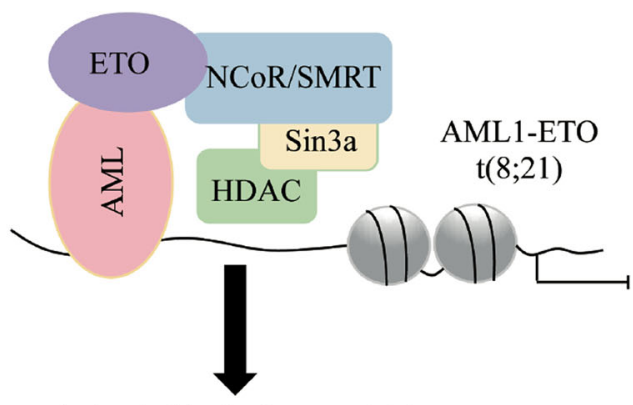

Differentiation is blocked at myeloblast stage

Fig. 3 A model highlights component transformation in transcriptional complex is critical for leukemic tranformation.

while this complex can be converted to the EKLF-p300/ CBP-SWI/SNF complex and promote $\beta$-globin expression during the differentiation of EBHX11L cells to a primitive erythroid phenotype [48] (Fig. 4). Similarly, the PU.1MeCP2-HDAC/mSIN3A complex inhibits the $\beta$-globin gene in undifferentiated MEL cells, and this complex is dissociated from the $\beta$-globin gene region during erythroid differentiation of MEL cells [49]. Interestingly, the acetylation state of the HDAC1/NURD complex plays a dual role during erythropoiesis. On the one hand, the HDAC1/NURD-GATA1 complex inhibits GATA2 expression by exerting deacetylation activity. On the other hand, p300-mediated acetylation of HDAC1 converts the NuRD complex from a repressor to an activator, which recruits GATA1 to promote $\beta$-globin expression and erythroid commitment $[6,50,51]$. Furthermore, the GfilbLSD1-CoREST-HDAC1/2 complex is recruited to the cmyc promoter, leading to histone $\mathrm{H} 3$ hypoacetylation and c-myc transcriptional repression. C-myc repression is required for the arrest of the cell cycle and the initiation of erythroid differentiation [52].

Moreover, HDAC and erythroid-specific TF interactions are critical for the regulation of the $\gamma$-globin gene. For instance, the Ikaros-GATA1-FOG1-HDAC1/NuRD complex is required for silencing the human $\gamma$-gene during $\gamma$ - to $\beta$-globin switching [53]. Diminished binding of acetylated NF-E4 to HDAC1 showed activation of $\gamma$ - globin and inhibition of $\beta$-globin in fetal erythroid cells [54]. In addition, inhibition of HDAC3-NCoR (nuclear receptor corepressor) complex activity by the HDAC3specific inhibitor SCFAD caused displacement of this complex from the $\gamma$-globin gene region with the recruitment of RNA polymerase II and upregulation of histones $\mathrm{H} 3$ and $\mathrm{H} 4$ acetylation status [55]. In contrast, HDAC9 might be recruited by MEF2 (myocyte enhancer factor 2 ) to the $\gamma$-globin gene promoter to mediate $\gamma$-globin activation and $\mathrm{HbF}$ synthesis during erythroid maturation of K562 cells [56]. Identification of HDACs-containing complex in association with globin gene switching may provide more molecular targets for intervening $\beta$-globin gene disorders.

The function of class II HDACs that shuttle other proteins between the cytoplasm and nucleus is critical for erythropoiesis. For instance, Watamoto et al. found that although HDAC5 didn't have deacetylation activity, it could shuttle GATA1 and EKLF from the cytoplasm to the nucleus via the formation of an erythroid-specific HDAC complex composed of HDAC5, GATA1, EKLF and ERK. Within the complex, the levels of p-ERK determine the shuttling activity of HDAC5. HDAC5 regulates the deacetylation levels of GATA1 and EKLF indirectly via the recruitment of HDAC3 to the complex $[4,5]$. During erythroid maturation, HDAC5, GATA1 and EKLF remain associated, but the levels of pERK

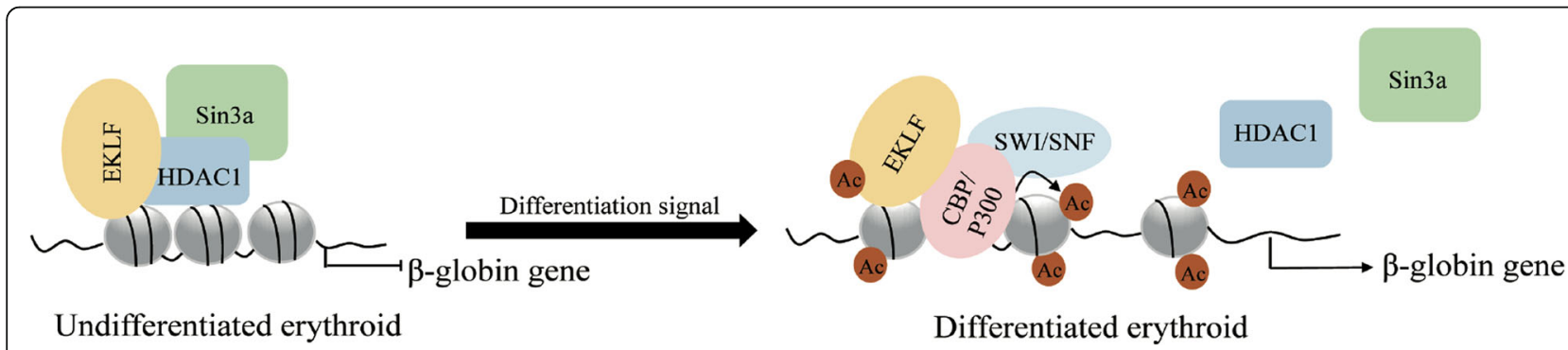

Fig. 4 A model of CBP/P300 and HDAC component patterns determines the transcriptional function of TF in erythroleukemia cell differentiation. 
sharply decrease, which inhibits $\gamma$-globin expression [4] (Fig. 5). Furthermore, erythropoietin signaling induces the phosphorylation of HDAC5 via PKD, which promotes the dissociation of HDAC5 from GATA1 and GATA1 acetylation. Mice lacking HDAC5 showed resistance to anemic challenge, enhanced progenitor entry into the erythroid lineage and accelerated erythroid maturation in response to erythropoietin [9]. HDACs are also involved in the enucleation process of erythroid terminal differentiation. To date, HDAC6 and HDAC2 have been shown to play a role in chromatin condensation and enucleation. The former could promote enucleation via deacetylation of $\mathrm{mDia} 2$ (mammalian Diaphanous-related formin) and formation of the contractile actin ring (CAR). While HDAC2 specifically enhances enucleation but not differentiation or proliferation, where potential mechanism still needs to be further investigated $[57,58]$.

\section{Lymphocyte lineages terminal differentiation}

The terminal differentiation of lymphoid lineages originates from common lymphoid progenitors (CLPs), which can be further divided into all-lymphoid progenitors (ALPs) and B cell-biased lymphoid progenitors (BLPs). ALPs retain the potential to generate B cells, $\mathrm{T}$ cells, natural killer cells and lymphoid dendritic cells, whereas BLPs are biased toward pre-B cells and immature $\mathrm{B}$ cells, and the latter migrate to the spleen to complete their maturation [59-61] (Fig. 2).

\section{B cell}

In early $B$ cell progenitors, simultaneous deletion of HDAC1 and HDAC2 resulted in a dramatic block in B cell development at the pre-B cell stage by inducing p21 and p57 expression, accompanied by G1 arrest and apoptosis induction [62]. During terminal B cell development, Blimp-1 represses c-myc via recruiting HDAC1 and HDAC2. In mature B cells, although the loss of both HDAC1 and HDAC2 has no effect on viability, the cells fail to proliferate and undergo apoptosis [63, 64].
Similarly, in E $\mu$-myc-driven B cell lymphomas, the ablation of HDAC1 and HDAC2 prevents $\mathrm{E} \mu$-myc tumorigenesis by decreasing proliferation and inducing apoptosis [65]. TFs have been found to mediate crosstalk between co-regulators in $\mathrm{B}$ cell development. For instance, the normal recruitment of HDAC1 by Ikaros is critical for the repression of the demethylase KDM58. In B-ALL, Casein kinase 2 (CK2)-mediated phosphorylation of Ikaros decreases HDAC1 recruitment to the KDM58 gene, which enhances KDM58 expression and leukogenesis [66, 67] (Fig. 6). For pregerminal center (GC) B cell differentiation, BCL6 RD2 domain-dependent recruitment of HDAC2 mediates repression of the trafficking receptors S1pr1 and Gpr183, contributing to the clustering of B cells within follicles [68]. Conditional knockdown of HDAC3 in early progenitor B cells of mice resulted in impaired $B$ cell maturation and a defect in VDJ recombination [69]. Specifically, HDAC3 is implicated in different complexes at different $B$ cell differentiation stages. For example, in pro-B cells, HDAC3 was identified as a component of the STAT5a-LSD1 complex, where it plays dual roles in determining the activation or repression of STAT5a [70]. In mature B cells, Bach2 recruits the HDAC3-NCoR1/NCoR2-Rif1 complex to repress Prdm1 transcription by deacetylating histone $\mathrm{H} 3-\mathrm{K} 9$, impeding the terminal differentiation of $\mathrm{B}$ cells into plasma cells [71].

HDAC-BCL6 complexes are implicated in the pathogenesis of lymphoma. For example, in normal GC B cells, CREBBP-regulated/active enhancers are counter regulated by the BCL6-SMRT-HDAC3 complex through a poised H3K27 deacetylation. However, in follicular lymphoma (FL) and diffuse large B cell lymphoma (DLBCL), CREBBP mutations disable its acetylation and result in unopposed deacetylation by the BCL6-SMRT-HDAC3 complex at enhancers of $\mathrm{B}$ cell signal transduction and immune response genes, thus promoting lymphomagenesis [72, 73]. In $\mathrm{B}$ cell non-Hodgkin lymphoma (B-NHL), aberrant expression of the HDAC9-BCL6 complex contributes to
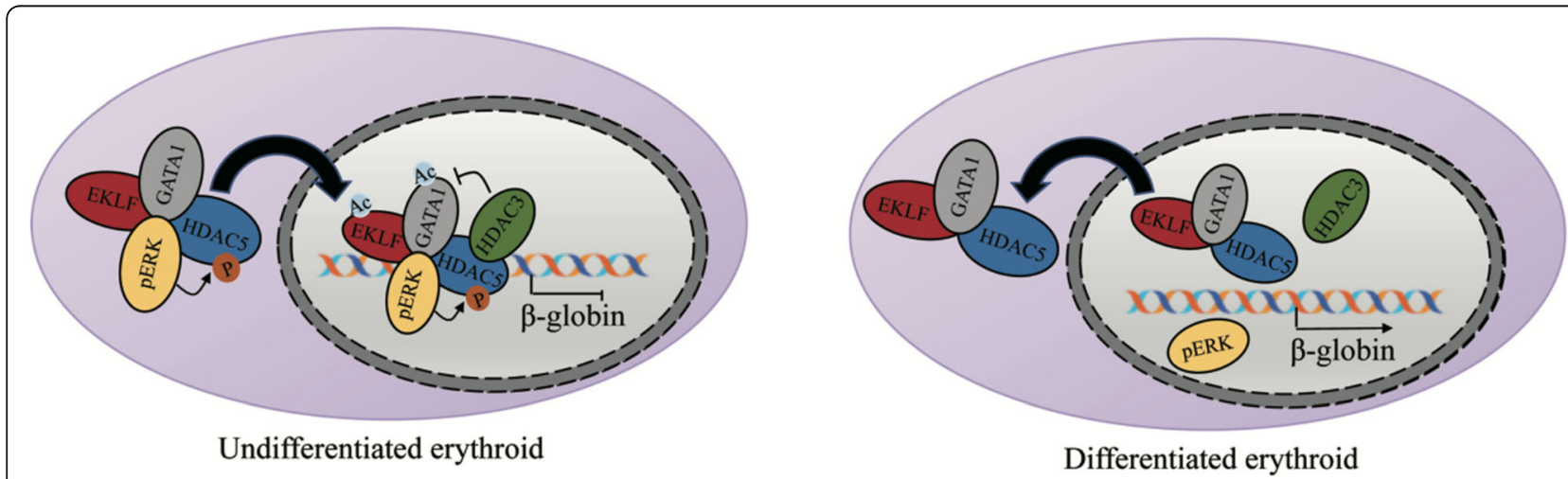

Fig. 5 A model of class II HDAC interaction patterns in erythroid differentiation. 


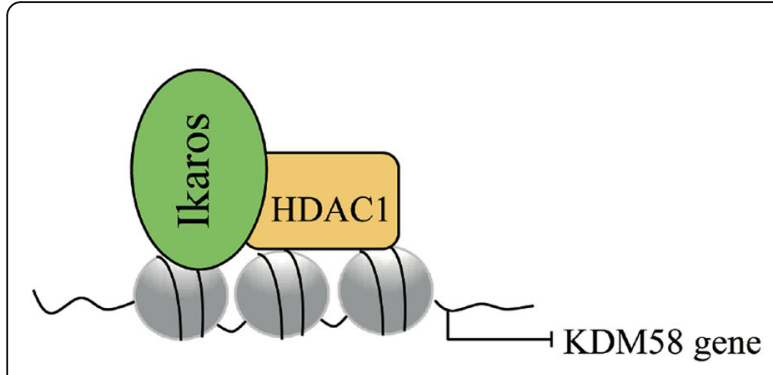

Normal B cell

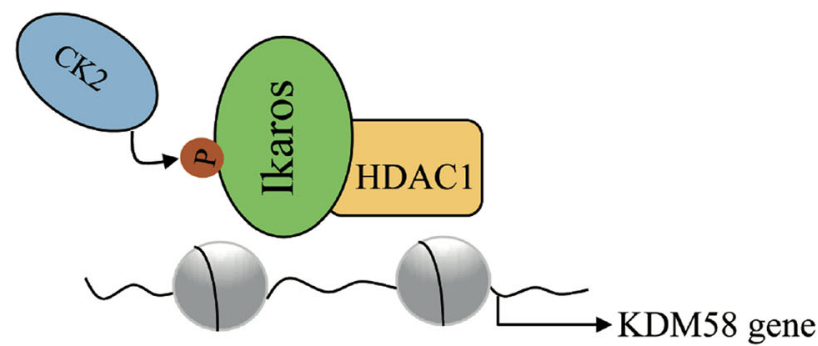

B-ALL cell

Fig. $6 \mathrm{~A}$ model of TF modification affects the recruitment of HDAC to the promoter.

lymphomagenesis by altering pathways involved in proliferation and survival, as well as modulating BCL6 activity and p53 tumor suppressor function [74]. In contrast, as a corepressor partner of BCL6, HDAC4 plays an important role in suppressing leukemogenesis in complexes with BCL6 that recruit HDAC4 to repress oncogenes [75]. For example, in miR-155-induced pre-B cell leukemia/lymphoma, miR-155 directly targets HDAC4 and causes disruption of the HDAC4-BCL6 complex activity, resulting in derepression of BCL6 targets that block B cell development at an immature B cell stage and induce uncontrolled cell proliferation [76]. Hence, the interactions with different HDACs could confer different functional properties to TFs.

Class IIa HDAC7 plays a physiological role in the lineage commitment of $\mathrm{B}$ cell progenitors. Conditional deletion of HDAC7 in mouse pro-B cells showed a block at the pro-B to pre-B cell transition, accompanied by severe lymphopenia in peripheral organs and pro- $B$ cell lineage promiscuity. HDAC7 specifically interacts with the transcription factor MEF2C in pro-B cells, and the HDAC7-MEF2C complex is involved in silencing lineage-inappropriate genes, ensuring correct $\mathrm{B}$ cell differentiation. In particular, HDAC7 is frequently underexpressed in pro-B-ALL and Burkitt lymphoma. Ectopically expressed HDAC7 interacts with the MEF2C-HDAC3-SMRT complex and suppresses c-Myc expression in both MEF2C- and self-catalytic activitydependent manners [61, 77, 78]. Conversely, HDAC7 appears to overexpressed in pre-B-ALL $\mathrm{t}(9 ; 22)$, B-ALL $\mathrm{t}$ (8;14), ALL t (12;21) and T-ALL (Fig. 7), which suggest different expression patterns for HDACs in different hematological malignancies. In addition, HDAC6 is suggested to play a role in the regulation of immunogenicity in CLL and MM. The HDAC6 inhibitor ACY1215 or HDAC6 specific silencing resulted in the downregulation of PD-L1 in primary B cells isolated from CLL patients and restoration of CD4:CD8 ratio [79]. Similarly, the HDAC6 inhibitor ACY241 significantly reduces the frequency of CD138+ MM cells, CD4 + CD25 + FoxP3+ regulatory $\mathrm{T}$ cells, and decreases expression of $\mathrm{PD} 1 / \mathrm{PD}$ -
L1 on CD8+ T cells in bone marrow cells from myeloma patients [80]. More recently, the combination of HDAC6 inhibitor and anti-PD-L1 antibody can trigger cytotoxic T lymphocytes and NK cell-mediated MM cell killing. A combination of HDAC6 inhibitor, anti-PD1 and lenalidomide further enhanced the anti-MM immune response of MM cells induced by HDAC6 inhibition [81]. Although some HDACis such as Panobinostat has been shown to exert toxic effects on lymphocytes while several studies showed a stimulation of CD8+ T-cells activation and function upon pan-HDACi treatment [82]. These studies suggest that reasonable selection of $\mathrm{HDACi}$ is critical for immunotherapy in hematological malignancies.

\section{$T$ cell}

During T cell development, HDAC1 and HDAC2 are essential for maintaining CD4 lineage integrity by inhibiting Runx3-CBF $\beta$ complexes that induce CD8 lineage programs in $\mathrm{CD} 4+\mathrm{T}$ cells. Loss of HDAC1 and HDAC2 at the early stages of $\mathrm{T}$ cell differentiation result in a severe reduction in thymocyte numbers due to a block in cell cycle progression at the pre-TCR stage. Loss of these cells during late $\mathrm{T}$ cell development leads to reduced numbers of peripheral $\mathrm{T}$ cells and the appearance of CD4+ CD8+ T cells (TH) [83]. Similarly, Dovey et al. found that disruption of the HDAC1/2-Sin3A-NuRD complex by deletion of HDAC 1 and HDAC 2 in T cells of neonatal mice resulted in a marked reduction in thymocyte cellularity, a block in double-negative (DN) to double-positive (DP) transition, and a failure to proliferate in response to $\mathrm{T}$ cell receptor (TCR) signaling. Moreover, HDAC1/2 haploinsufficiency in mice causes a lethal pathology by $\mathrm{T}$ cell lymphomas with global histone acetylation and chromosomal instability [84], indicating an essential role for $\mathrm{HDAC} 1 / 2$ in the development of mature $\mathrm{T}$ cell populations and in maintaining genome stability.

HDAC3 is required for multiple stages in T cell development, including CD4 and CD8 lineage commitment, 


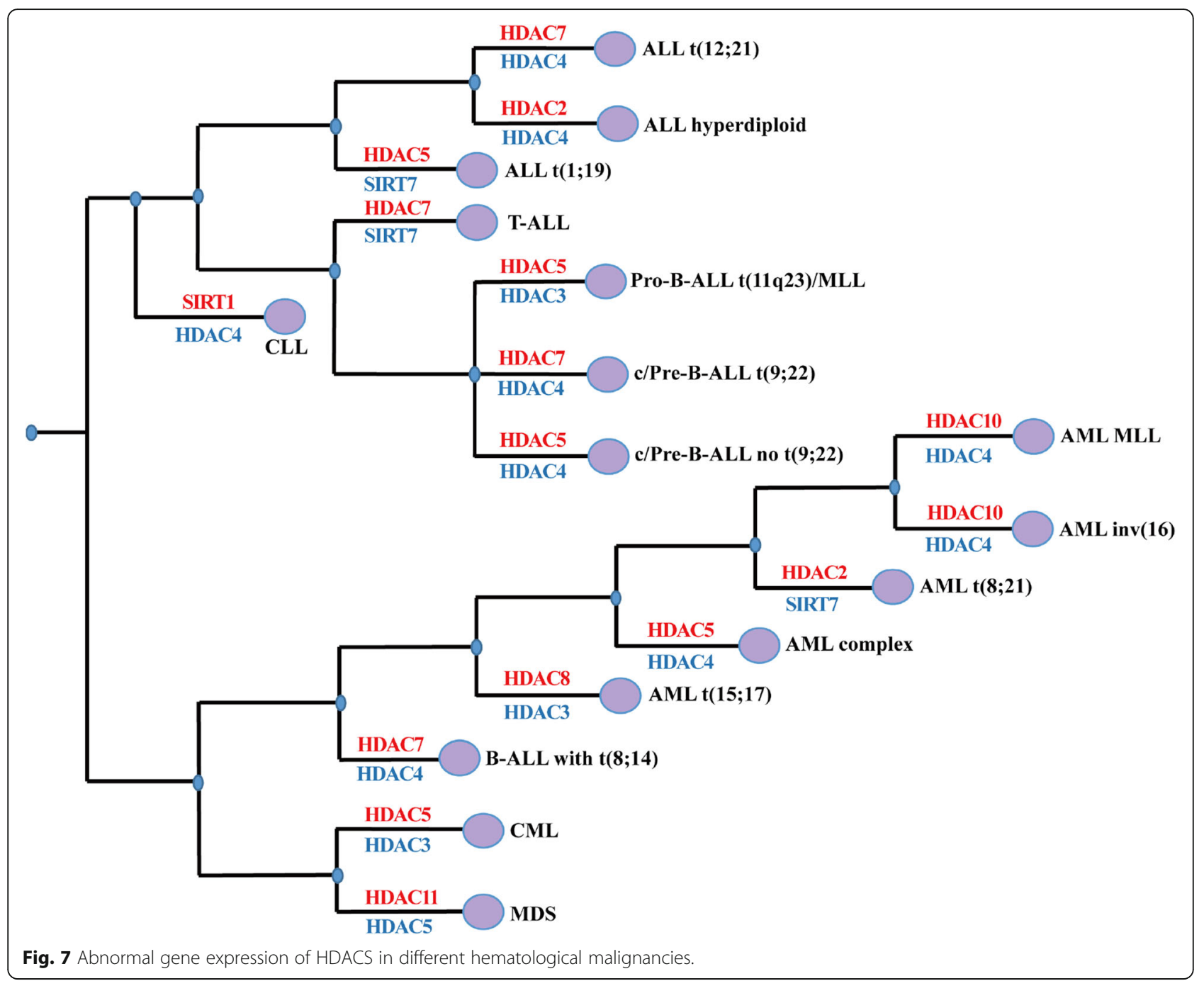

positive selection and peripheral $\mathrm{T}$ cell maturation. Specifically, HDAC3-deficient DP thymocytes fail to induce the CD4-lineage program and accelerate the redirection of MHC class II-restricted thymocytes to the CD8 lineage prior to positive selection with an increase in histone acetylation of CD8-lineage genes, such as Runx3 and Patz1 [85]. HDAC3 is required for positive selection of thymocytes. T cell development in CD2-icre HDAC3 conditional knockout (cKO) mice was blocked at positive selection due to a failure to downregulate ROR $\gamma$ t (retinoic acid-related orphan receptor) and upregulate Bcl-2, which led to few CD4 and CD8 T cells. ChIP assays revealed that HDAC3 directly deacetylates histones to inhibit RORyt gene expression. The deletion of RORyt and transgenic expression of Bcl-xl corrects the positive selection defect in HDAC3-cKO mice [86]. HDAC3 is also required for $\mathrm{T}$ cell development from DN stage 4 into the early CD4/CD8 DP stage. The deletion of HDAC3 in the DN stage of thymocyte development by Lck-Cre-transgene caused a significant impairment at the CD8 immature single-positive (ISP) stage and the CD4/CD8 (DP) stage. When $\mathrm{HDAC}^{-/-}$ mice were crossed with $\mathrm{Bcl}-\mathrm{xl}-, \mathrm{Bcl} 2-$, or TCR $\beta$-expressing transgenic mice, CD4 and CD8 SP cells were partially rescued [87]. The NKAP-HDAC3 complex is required for post-thymic $\mathrm{T}$ cell maturation. The majority of HDAC3deficient naïve $\mathrm{T}$ cells are recent thymic emigrants (RTEs), which cannot become long-lived naïve T cells. HDAC3deficient peripheral $\mathrm{T}$ cells have a defect in TNF licensing after TCR/CD28 stimulation [88]. Moreover, the HDAC3NCoR1/2-SMRT complex is essential for the normal development and suppressive functions of thymic and peripheral FOXP3 ${ }^{+} \mathrm{T}$ regulatory cells (Tregs) via association with FOXP3. The enzymatic activity of HDAC3 can be enhanced by NCoR1 or NCoR2/SMRT, which, in turn, deacetylates histone $\mathrm{H} 3$ at the IL-2 promoter and inhibits IL2 transcription in FOXP3 ${ }^{+}$Tregs [89]. Therapy with pan HDACi such as TSA or SAHA can stimulate the thymic production of FOXP3+ Tregs and promote the peripheral conversion of murine and human $\mathrm{T}$ cells into Tregs [90]. 
Class IIa HDAC7 plays a role in life/death decisions in thymic $\mathrm{T}$ cell development. HDAC7 is exported from the nucleus by PKD during positive selection in thymocytes, and it regulates genes mediating the coupling between TCR engagement and downstream events that determine cell survival. Thymocytes lacking HDAC7 are inefficiently positively selected due to a severely shortened lifespan and exhibit a truncated repertoire of TCR Ja segments [91, 92]. Class IIa HDAC5 is implicated in Treg homeostasis. $\mathrm{HDAC}^{-1-}$ mice showed reduced suppressive function and a decrease in Foxp3 in Tregs. CD4+ T cells lacking HDAC5 impair the ability of T effector cells to convert into induced Tregs. CD8+ T cells missing HDAC5 have a reduced ability to produce the cytokine of IFN- $\gamma$ [93]. Class IV HDAC11 serves as a negative regulator of the $\mathrm{T}$ effector cell phenotype and function. T cells lacking HDAC11 show increased proliferation and proinflammatory cytokine production, such as IL- 2 and IFN- $\gamma$, and inhibited tumor progression in murine lymphoma [94]. Specifically, HDAC11 and HDAC6 physically interact with each other and are simultaneously recruited to the IL-10 gene in antigenpresenting cells (APCs), where HDAC6 and HDAC11 act as a transcription activator and repressor of IL-10 expression, respectively [95]. Their dynamic interaction and the dynamic changes in the expression of IL-10 are suggested to explain the intrinsic plasticity of APCs in determining $\mathrm{T}$ cell activation versus $\mathrm{T}$ cell tolerance.

\section{The clinical implications of HDACis in malignant hematopoiesis}

Aberrant expression of HDACs is linked to hematological malignancies, such as leukemias and lymphomas (Fig. 7). Specifically, the overexpression of HDAC5 and HDAC7 is associated with ALL, CML and AML. Low expression of
HDAC4 is widespread in ALL, CML and AML [96-98]. To date, little is known about the mutation status and copy number alteration of HDACs in malignant hematopoiesis. However, by analyzing the TCGA database, we found that HDAC1, 4, 7 exhibited both gene mutations and CNAs in DLBCL, suggesting a key etiology for these HDACs (Table 2). However, their pathogenic mechanisms still need to be further investigated.

Furthermore, HDACs are critical for the optimal oncogenic activity of leukemia fusion proteins. For example, AML1-ETO, PML-RAR $\alpha$ and RAR $\alpha$-PLZF cause transcriptional repression of genes responsible for hematopoietic differentiation via recruitment of $\mathrm{HDAC} 1 / 3$, thus contributing substantially to leukemogenesis [99-107]. Given that the expression and activity of HDACs are closely related to the etiology of hematological malignancies, HDACs are hot targets for clinical drug development.

\section{The application of HDACis in malignant hematopoiesis} HDACis represent a class of cytostatic agents that interfere with the function of HDACs and are able to directly or indirectly regulate gene expression by inducing acetylation of histones or nonhistone proteins, involving cellcycle arrest, promotion of differentiation or apoptosis and have different kinetics and activities depending on their chemical structures (Fig. 8). Generally, normal cells are often less sensitive to HDACis than tumor cells, and many HDAC inhibitors are undergoing extensive clinical evaluation as single agents and in combination with other chemotherapeutics $[108,109]$. To date, panobinostat and belinostat have received FDA approval for the treatment of MM and NHL respectively. In addition, panobinostat, belinostat, romidepsin, entinostat and mocetinostat are in phase I, II or III clinical trials alone or in combination with other drugs for the treatment of

Table 2 HDACs with mutations or abnormal copy numbers in hematological malignancies

\begin{tabular}{|c|c|c|c|c|c|c|c|c|}
\hline \multirow[b]{2}{*}{ Disease } & \multirow[b]{2}{*}{ Gene } & \multicolumn{3}{|c|}{ Gene mutations } & \multicolumn{4}{|c|}{ Copy number alteration (CNA) } \\
\hline & & $\begin{array}{l}\text { Mutation } \\
\text { number }\end{array}$ & $\begin{array}{l}\text { Case number with } \\
\text { mutation }\end{array}$ & $\begin{array}{l}\text { Percentage (total } \\
\text { number) }\end{array}$ & Cytoband & Type of CNA & $\begin{array}{l}\text { Case number } \\
\text { with CNA }\end{array}$ & $\begin{array}{l}\text { Percentage (total } \\
\text { number) }\end{array}$ \\
\hline \multirow[t]{2}{*}{ AML } & HDAC4 & 2 & 2 & $0.3 \%(622)$ & NA & NA & NA & NA \\
\hline & HDAC7 & NA & NA & NA & $12 q 13.11$ & DEL (deletion) & 1 & $0.5 \%(191)$ \\
\hline CLL & HDAC4 & 1 & 1 & $0.2 \%(506)$ & NA & NA & NA & NA \\
\hline \multirow[t]{4}{*}{ DLBCL } & HDAC1 & 1 & 1 & $0.7 \%(135)$ & $\begin{array}{l}\text { 1p35.2- } \\
\text { p35.1 }\end{array}$ & DEL (deletion) & 1 & $2.1 \%(48)$ \\
\hline & HDAC4 & 3 & 2 & $1.5 \%(135)$ & $2 q 37.3$ & $\begin{array}{l}\text { AMP } \\
\text { (amplifications) }\end{array}$ & 1 & $2.1 \%(48)$ \\
\hline & HDAC7 & 1 & 1 & $0.7 \%(135)$ & $12 q 13.11$ & $\begin{array}{l}\text { AMP } \\
\text { (amplifications) }\end{array}$ & 2 & $4.2 \%(48)$ \\
\hline & & & & & & DEL (deletion) & 1 & $2.1 \%(48)$ \\
\hline MM & HDAC7 & 1 & 1 & $0.5 \%(205)$ & NA & NA & NA & NA \\
\hline $\mathrm{NHL}$ & HDAC7 & 1 & 1 & $7.1 \%(14)$ & NA & NA & NA & NA \\
\hline
\end{tabular}




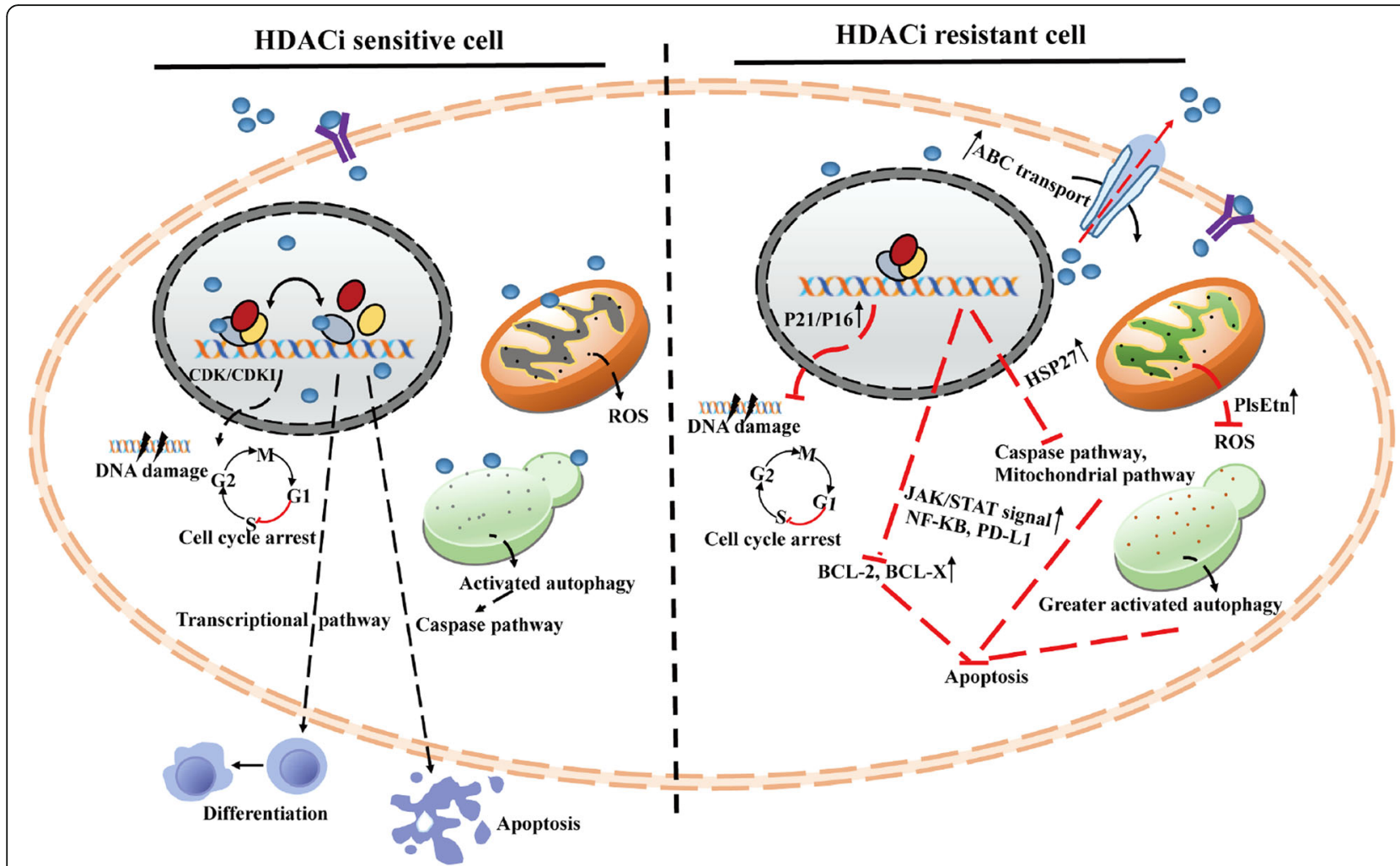

Fig. 8 Sensitivity and resistance mechanisms of hematological malignancies to HDACis.

other hematological malignancies (Fig. 1 and Table 3). Although, hydroxamate-based HDACis attract much attention in development of HDACi inhibitors, based on their remarkable zinc chelating capability. Nevertheless, it should be noted that some pan-HDACis, like romidepsin, panobinostat and vorinostat, display adverse effects, such as poor oral absorption, metabolic and pharmacokinetic problems because of glucuronidation, sulfation and enzymatic hydrolysis that lead to a short in vivo half-life [109]. Moreover, hydroxamate group can give rise to multiple off-target and mutagenic effects resulting from the coordination of other metalloenzymes, leading to undesirable adverse effects, such as nausea, thrombocytopenia, anemia and other metabolic issues, which may limit their clinical applications and promote the development of a new class of HDAC isoform-selective antagonists with reducing adverse effects $[7,110]$.

Acquirement of the crystal structure of a given HDAC isoform combined with kinetic studies may contribute to overcome the structural homology between HDACs. For example, the availability of crystal structures of unique catalytic channels, such as catalytic domains CD1 and CD2 of HDAC6 and an acetate release channel of HDAC8, provided a unique strategy to develop their selective antagonists [111]. For the entrance ring area of catalytic channel, isoform selectivity could be achieved by designing zinc-binding groups bearing substituents that make specific interactions into the foot pocket (HDAC1-3) or into the lower pocket (class IIa HDACs) of a given isoform. For example, replacement of serine 107 by tyrosine in HDAC3 leads to a spatially restricted foot pocket that can be exploited to develop antagonists selective for class I HDACs [112]. Furthermore, the choice of surface-binding motifs that make specific interactions with the external characteristic grooves of the desired isoform, or targeting specific surfaces between HDACs and interacting partners that are critical for efficient deacetylase activity, such as the Ins $(1,4,5,6) \mathrm{P} 4$ binding site for HDAC1-3 or the CCHC zinc-binding motif for class IIa HDACs, might contribute to gain selectivity [113]. Finally, subtle structural differences in the hydrophobic active site channel have been exploited toward selective inhibitor design. Specifically, favorable interactions with a unique sub-pocket in the hydrophobic active site channel led to the creation of HDAC8-selective inhibitors $[7,114]$.

In addition, overcoming tumor heterogeneity and drug resistance promotes the development of combination treatment for HDACis. For example, a phase I study of vorinostat with decitabine-treated R/R AML patients who had mixed lineage leukemia (MLL) demonstrated a $35 \%$ composite complete response (CRC) rather than a 
Table 3 HDACis in combination with other anticancer agents in phase I/II/III clinical trials

\begin{tabular}{|c|c|c|c|}
\hline HDACis & Combination(s) & Cancer(s) & Clinical trial \\
\hline \multirow[t]{21}{*}{ Vorinostat } & Sorafenib & $\mathrm{AML}, \mathrm{APL}, \mathrm{MDS}$ & I \\
\hline & Carfilzomib & B-cell lymphoma & । \\
\hline & Zolinza & Lymphoma or Leukemia & $|/| \mid$ \\
\hline & Azacitidine & AML,MDS & $\|$ \\
\hline & Temozolomide & AML & $\|$ \\
\hline & Rituximab & Lymphoma & $\|$ \\
\hline & \multirow[t]{2}{*}{ Decitabine } & AML, ALL, CLL, Lymphoma & । \\
\hline & & MDS & $\|$ \\
\hline & Alisertib & Lymphoma & । \\
\hline & Alvocidib & $\mathrm{AML}, \mathrm{CML}, \mathrm{ALL}$ & । \\
\hline & Isotretinoin & APL,AML, Lymphoma & । \\
\hline & Idarubicin & $\mathrm{AML}, \mathrm{CML}, \mathrm{MDS}$ & । \\
\hline & Idarubicin, Cytarabine & AML, MDS & $\|$ \\
\hline & Sorafenib, bortezomib & AML & $|/| \mid$ \\
\hline & Cytarabine, Decitabine & $\mathrm{AML}, \mathrm{MDS}$ & । \\
\hline & AMG655, Bortezomib & Lymphoma & । \\
\hline & Lenalidomide, Azacitidine & $C M L, M D S$ & $\|$ \\
\hline & Lenalidomide, Dexamethasone & MM & । \\
\hline & Bortezomib, Dexamethasone & $\mathrm{MM}$ & $\|$ \\
\hline & Gemtuzumab, Ozogamicin, Azacitidine & AML & $|/| \mid$ \\
\hline & Tacrolimus, Cyclosporine, Methotrexate & CML, AML, Lymphoma & $\|$ \\
\hline \multirow[t]{19}{*}{ Panobinostat } & Carfilzomib & MM & $|/| \mid$ \\
\hline & Bortezomib & T-cell lymphoma, MM & $\|, \mid$ \\
\hline & Everolimus & Lymphoma & $|/| \mid$ \\
\hline & Lenalidomide & $\mathrm{HL}, \mathrm{MM}$ & $\|$, I \\
\hline & Placebo & $\mathrm{HL}$ & III \\
\hline & Melphalan & MM & $|/| \mid$ \\
\hline & Cytarabine & Leukemia, NHL & । \\
\hline & 5-Azacytidine & AML, MDS, CMML & । \\
\hline & Decitabine & $\mathrm{AML}, \mathrm{MDS}$ & $|/| \mid$ \\
\hline & Everolimus & Lymphoma & $|/| \mid$ \\
\hline & Imatinib mesylate & Leukemia & । \\
\hline & Lenalidomide, Dexamethasone & MM & $\|$ \\
\hline & Carfilzomib, Dexamethasone & MM & । \\
\hline & Bortezomib, Dexamethasone & MM & $\|$ \\
\hline & Bortezomib, Placebo & $\mathrm{MM}$ & III \\
\hline & Dexamethasone, MLN9708 & MM & $\|$ \\
\hline & Dexamethasone, Lenalidomide, Bortezomib & MM & । \\
\hline & Cytarabine, Daunorubicin & AML, MDS & । \\
\hline & Ifosfamide, Mesna, Carboplatin, Etoposide, Pegfilgrastim & $\mathrm{HL}$ & $|/| \mid$ \\
\hline \multirow[t]{4}{*}{ Belinostat } & Carfilzomib & Peripheral T-cell lymphoma, NHL, DCBCL, FL & । \\
\hline & Rituximab & Lymphoma & $\|$ \\
\hline & Idarubicin & AML & $|/| \mid$ \\
\hline & Bortezomib & AML,ALL,MDS,CML & । \\
\hline
\end{tabular}


Table 3 HDACis in combination with other anticancer agents in phase I/II/III clinical trials (Continued)

\begin{tabular}{|c|c|c|c|}
\hline HDACis & Combination(s) & Cancer(s) & Clinical trial \\
\hline \multirow[t]{3}{*}{ VPA } & Decitabine & AML, MDS & $\|$ \\
\hline & 5-azacytidine & $\mathrm{AML}, \mathrm{MDS}$ & $\|$ \\
\hline & Rituximab, Cyclophosphamide, Doxorubicin, Vincristine, Prednisone & DLBCL & $|/| \mid$ \\
\hline \multirow[t]{2}{*}{ Romidepsin } & Gemcitabine, dexamethasone and cisplatin & $\mathrm{DCBCL}$ & । \\
\hline & 5-azacitidine & Relapsed/refractory lymphoid maligancies & $|/| \mid$ \\
\hline \multirow[t]{2}{*}{ Mocetinostat } & Brentuximab vedotin (SGN-35) & $\mathrm{HL}$ & $|/| \mid$ \\
\hline & Azacitidine & MDS, AML & $|/| \mid$ \\
\hline \multirow[t]{2}{*}{ AR42 } & Decitabine & AML & । \\
\hline & Pomalidomid & MM & 1 \\
\hline Entinostat & Sorafenib tosylate & AML & 1 \\
\hline 4-PBA & Azacitidine & $\mathrm{AML}, \mathrm{MDS}$ & । \\
\hline SB939 & Azacitidine & Hematologic Malignancies, MDS & । \\
\hline
\end{tabular}

$17 \%$ overall response rate (ORR) of vorinostat monotherapy [115]. Hence, combining HDACis with other chemotherapeutic agents is considered to be an effective way to enhance tumor drug sensitivity by improving the cellular efficacy and toxicity of HDACis to tumor cells [116-125] (Table 3 and Table 4). To date, the different mechanisms of HDACis combined with chemotherapeutic agents such as topoisomerase inhibitors, platinumbased chemotherapeutics, proteasome inhibitors, tyrosine kinase pathway inhibitors and epigenetic modifiers for advanced or drug-resistant hematological malignancies include (1) acetylating histones and inducing p21CDK-mediated cell cycle arrest; (2) inducing apoptosis by regulating the expression of pro- and antiapoptotic genes through the intrinsic or extrinsic pathway; (3) inducing DNA damage and oxidative stress; (4) activating BTK (in CLL) or inhibiting ERK (in MM) and AKT (in CML) signaling pathways; and (5) regulating the expression of drug resistance-related molecules, such as downregulating $\mathrm{BCR}-\mathrm{ABL}$ and upregulating $\mathrm{Bim}$ in hematological malignancies and downregulating CD44 in multiple myeloma (MM), NF- $\mathrm{KB}$ in ALL, $\gamma$-catenin in CML, and BRCA1, CHK1 and RAD51 in AML [126-145]. Specific combination strategies and their corresponding mechanisms are summarized in Table 3 [146-155]. Moreover, two-phase I clinical trials were carried out to assess the DNA methyltransferase (5-azacitidine) and HDACi (phenylbutyrate) for the treatment of hematological malignancies. A combination of BCL6 inhibitor (RI-BPI) with HDAC inhibitor (HDI) enhanced RI-BPI killing of primary human DLBCL cells in vitro $[156,157]$. These studies suggest that the combination of HDACis with HDACinteracting molecule inhibitors, such as TF inhibitors, chromatin remodeling molecule inhibitors or histone/ DNA-modifying co-regulator inhibitors, is a potential combination strategies for hematological malignancies. However, optimizing combination scheduling and doses are necessary for avoiding pharmacological antagonism. For example, the combination of Vorinostat, Bortezomib and Pegylated liposomal doxorubicin (PLD) is suffering from the withdraw in phase I trials of MM. Since whole blood proteasome activity assays demonstrated a potential impact of Vorinostat on the chymotryptic-like activity of the proteasome [158].

NIH clinical trial database: www.clinicaltrials.gov. (These trials have been completed or are in active).

\section{Drug resistance mechanisms}

Although HDACis play a tremendous role in improving patient survival and symptom control, in most cases, hematological malignancy cells develop drug resistance to HDACis, resulting in malignant phenotype regeneration and maintenance. Resistant-related proteins and abnormal in epigenetic or genetic factors and pathways are implicated in resistance to HDACis, including drug efflux, target status, chromatin alteration, upregulation of oxidative stress response mechanism, defects in proapoptotic pathways, and upregulation of antiapoptotic signals/stimuli (Fig. 8). For instance, SAHA induced multidrug resistance-related $\mathrm{ABC}$ transporter genes (MDR1, BCRP, MRP7, and MRP8) in leukemia cells. Overexpression of these cellular pumps has side effects on broad-spectrum drug resistance and cell intake. Changing the permeability proprieties of HDACis, adjusting the sequence of treatment or adopt nanopackaging materials may improve the efficacy of HDACis [159]. Furthermore, HSP72, as the most overexpressed protein in CTCL cell lines, induces chemoresistance against SAHA and VPA by suppressing the activation of caspase-3/8/9 and the mitochondrial pathway of Bcl-2 and reducing HDACi-induced histone H3 acetylation [160]. Highly elevated peroxisomes protect vorinostat-resistant lymphoma cells from ROS damage via two antioxidant mechanisms: (1) upregulating 
Table 4 Mechanisms of HDACis combined with other agents in treating malignant hematopoiesis at preclinical settings

\begin{tabular}{|c|c|c|c|}
\hline HDACis & Combination(s) & Cancer(s) & Mechanism(s) \\
\hline \multirow{11}{*}{$\begin{array}{l}\text { Vorinostat } \\
\text { (SAHA) }\end{array}$} & \multirow[t]{2}{*}{ Bortezomib } & Relapsed/refractory MM & Increasing p21 and cleaved PARP expression \\
\hline & & T-ALL & Inhibiting NF-KB signaling \\
\hline & Carfilzomib or Bortezomib & $\begin{array}{l}\text { Relapsed/refractory B } \\
\text { cell lymphomas }\end{array}$ & Decreasing NF-KB activation and increasing Bim levels \\
\hline & Rituximab & Lymphoma/leukemia & $\begin{array}{l}\text { Increasing in p21 and acetylation of histone } \mathrm{H} 3 \text { leading to cell cycle } \\
\text { arrest }\end{array}$ \\
\hline & ABT-737 & DLBCL & Inhibiting binding of $\mathrm{BH} 3$-only modulators and proapoptotic activators \\
\hline & MG-132 & Imatinib-resistant CML & Increasing intracellular ROS and repressing BCR-ABL expression \\
\hline & S116836 & Imatinib-resistant CML & $\begin{array}{l}\text { Repressing antiapoptosis proteins } \mathrm{MCl}-1 \text { and XIAP, promoting Bim expres- } \\
\text { sion and mitochondrial damage }\end{array}$ \\
\hline & BI2536 & Imatinib-resistant CML & $\begin{array}{l}\text { Triggering pronounced mitochondrial dysfunction, generating reactive } \\
\text { oxygen species (ROS) and DNA damage }\end{array}$ \\
\hline & KW-2449 & $\begin{array}{l}\text { Imatinib-resistant CML / } \\
\text { AML }\end{array}$ & Inhibiting Bcr/Abl and inducing ROS and DNA damage \\
\hline & ABT-737 & Emu-myc lymphomas & Repressing BCR-ABL expression \\
\hline & Idarubicin + Cytarabine & $\begin{array}{l}\text { Advanced AML or Aza- } \\
\text { resistant MDS }\end{array}$ & Generating reactive oxygen species (ROS) \\
\hline \multirow[t]{7}{*}{$\begin{array}{l}\text { Panobinostat } \\
\text { (LBH589) }\end{array}$} & Bortezomib & Relapsed/refractory TCL & $\begin{array}{l}\text { Increasing acetylation of HSP90, downregulating mitogen-activated pro- } \\
\text { tein kinase pathway signaling }\end{array}$ \\
\hline & Carfilzomib & Relapsed/refractory MM & Inhibiting p97, HDAC or PI3Ka \\
\hline & Ibrutinib & Relapsed/refractory MM & Generating ROS and inactivating ERK1/2 \\
\hline & ABT-199 & Ibrutinib-resistant CLL & Reducing BTK/mutated BTK protein and signaling \\
\hline & Ponatinib or Imatinib & AML & Upregulating Bim expression \\
\hline & Everolimus & Imatinib-resistant CML & Forcing histone acetylation and decreasing BCR-ABL and AKT signaling \\
\hline & Everolimus & $\mathrm{HL} / \mathrm{NHL}$ & $\begin{array}{l}\text { Activating the caspase pathway, inhibiting STAT5 and STAT6 } \\
\text { phosphorylation, GLUT1 and mTOR }\end{array}$ \\
\hline \multirow[t]{5}{*}{ Romidepsin } & Rituximab & Rituximab-resistant BL & Decreasing phosphorylated STAT3 binding to the MyD88 promotor \\
\hline & EXPBNK & $\mathrm{BL}$ & Reducing p38 MAPK phosphorylation and enhancing MICA/B expression \\
\hline & Ara-C & AML & $\begin{array}{l}\text { Enriching Myc- and HOXA9-regulated gene pathways and inducing cell } \\
\text { cycle arrest and DNA damage }\end{array}$ \\
\hline & ATRA & APL & Inducing p21-mediated cell-cycle arrest and the expression of MDR1 \\
\hline & $\begin{array}{l}\text { Gemcitabine, cisplatin and } \\
\text { dexamethasone }\end{array}$ & DLBCL & Reducing LMP1 and c-myc expression \\
\hline \multirow[t]{2}{*}{ Belinostat } & Vincristine or Paclitaxel & DLBCL & Inducing mitosis arrest and apoptosis \\
\hline & Bortezomib & $\mathrm{AML} / \mathrm{ALL}$ & Inhibiting NF-KB signaling and upregulating Bim expression \\
\hline \multirow[t]{2}{*}{ Entinostat } & Sorafenib & Refractory/relapsed AML & Inhibiting HOXA9, MEIS1 and FLT3 \\
\hline & KW-2449 & $\begin{array}{l}\text { Imatinib-resistant CML / } \\
\text { AML }\end{array}$ & Inhibiting Bcr/Abl, inducing ROS and DNA damage \\
\hline \multirow[t]{4}{*}{ Valproic acid } & Decitabine & AML or MDS I/II & Inducing cell cycle arrest, DNA damage and apoptosis \\
\hline & TRAIL/Apo2L & $\begin{array}{l}\text { TRAIL/Apo2L-resistant } \\
\text { CML }\end{array}$ & Increasing DR4 and DR5 expression \\
\hline & ABT-737 & Emu-myc lymphomas & Restricting $\mathrm{BCl}-2$ and $\mathrm{BCl}-\mathrm{X}_{\mathrm{L}}$ \\
\hline & Chloroquine (CQ) & AML & Inducing RASSFIA expression and inhibiting autophagy \\
\hline \multirow[t]{3}{*}{ MGCD0103 } & Cytarabine or daunorubicin & AML & Inducing DNA damage and apoptosis \\
\hline & Brentuximab vedotin & Relapsed/refractory HL & N/A \\
\hline & Azacitidine & High-risk MDS or AML & Increasing p15 and caspase-3 expression \\
\hline \multirow[t]{2}{*}{ AR-42 } & Decitabine & M5 subtype-AML & Elevating miR-199b expression \\
\hline & Lenalidomide & $\begin{array}{l}\text { Lenalidomide-resistant } \\
\text { MM }\end{array}$ & Upregulating miR-9-5p, downregulating IGF2BP3 and CD44 \\
\hline
\end{tabular}


Table 4 Mechanisms of HDACis combined with other agents in treating malignant hematopoiesis at preclinical settings (Continued)

\begin{tabular}{llll}
\hline HDACis & Combination(s) & Cancer(s) & Mechanism(s) \\
\hline Depsipeptide & ATRA & APL & Upregulating of MDR1 and inducing p21-mediated cell cycle arrest \\
SBHA & ABT-737 & Relapsed/refractory MM & Upregulating Bim expression and disabling cytoprotective autophagy \\
JSL-1 & Imatinib & Imatinib-resistant CML & Inhibiting r-catenin \\
$\begin{array}{l}\text { Sodium } \\
\text { phenylbutyrate }\end{array}$ & Azacitidine & AML or MDS & Reducing endoplasmic reticulum (ER) stress and ablating CHOP protein \\
\hline
\end{tabular}

Notes: NA Not applicable

catalase and (2) increasing the levels of plasmalogens (PlsEtn) and related genes (such as GNPAT, FAR1 and FAR2) [161]. High levels of HSPA1A is associated with VPA resistance in lymphoid neoplasms. Inhibition of HSPA1A by KNK-437 could resensitize cells to VPAinduced apoptosis [162]. Furthermore, the phosphoproteins MAPKAPK2, ACTB, HSP90AA1 and HSP90AB1 were considered resistance hubs in VPA-resistant AML cell lines [163].

Altered levels of antiapoptotic proteins drive resistance against HDACi-mediated apoptosis. Specifically, it has been observed that increased JAK/STAT signaling negatively affects HDACi-induced death of CTCL cells and that high levels of phosphorylated STAT 3 is correlated with a lack of response to vorinostat [164]. Consistently, elevated levels of the antiapoptotic proteins BCL-2 and $\mathrm{Bcl}-\mathrm{xL}$ show strong resistance to vorinostat-induced apoptosis in DLBCL cell lines [119]. Similarly, NF- $\kappa B$ upregulation confers Hodgkin's lymphoma (HL) cell resistance to MGCD0103 and panobinostat by interfering with apoptosis [165]. Moreover, significant induction of $\mathrm{NF}-\mathrm{KB}$ and its upstream regulator PD-L1 were found to be related to the resistance of myelodysplastic syndrome (MDS) and AML to LBH-589 therapy [166]. CDK inhibitors also act as key resistance-inducing factors. P21 and p27 have sustained overexpression in DLBCL, inhibiting cell cycle arrest and cell death induced by PXD101 [167]. Overexpression of p 21 and p16 induces G1 arrest, increases SAHA- and depsipeptide-induced antiapoptotic genes and decreases proapoptotic genes in acute $\mathrm{T}$ cell leukemia cells [168]. Upregulation of p21 in acute promyelocytic leukemia (APL) cells attenuates HDACiinduced DNA damage and cell cycle arrest, which is correlated with DNA repair [167].

The generation of ROS is one of the key mechanisms by which HDACis induce cell death in malignant cells. However, the increased expression of vorinostat-induced antioxidant genes, such as glutathione (GSH), glutamate cysteine ligase (GCL) and superoxide dismutase (SOD), is related to HDACi resistance in advanced AML and MDS $[169,170]$. In addition, properly activated autophagy promotes apoptosis in HDACi-treated cells. Conversely, a study showed that excessive activation of autophagy is necessary to protect the vorinostat-resistant lymphoma cell line and DLBCL cell line from apoptosis. HDAC6 deacetylation of HSP90 mediates chaperone complex assembly, and excessive autophagy to remove accumulated misfolded/aggregated proteins is considered a protective mechanism of autophagy against vorinostat-resistant cells [171]. To date, remarkably little is known about HDACi-induced multidrug resistance at single-cell levels. Elucidation of resistant mechanisms using a series of single-cell sequencing may contribute to overcome tumor heterogeneity for HDACi-resistance.

\section{Conclusion}

As key deacetyltransferase subunits of multiprotein complexes, they regulate histone affinity for DNA and chromatin accessibility to their cognate binding proteins by compaction of DNA/histone complexes. Their biochemical and molecular characterization significantly affects the deacetyltransferase activity of HDAC-containing complexes. Importantly, the catalytic/noncatalytic and histone/nonhistone effects of HDACs on hematopoietic cells confer their ability to regulate a variety of cellular events in normal and malignant hematopoiesis. HDAC actions are gene or environment specific during hematopoiesis: (1) Different genes regulated by the same HDAC require the recruitment of different coregulators. For instance, HDAC1 has been found in at least three multiprotein complexes, including Sin3, CoREST and NuRD complexes. (2) One HDAC can act as a coactivator or corepressor on different genes and utilize different domains to act on interacting proteins. For instance, HDAC1-containing $\mathrm{NuRD} / \mathrm{MeCP} 1$ corepressor complexes play an important role in GATA-1-mediated repression of target genes (i.e., GATA-2, $\gamma$-globin, c-myc, c-kit and Hes1), which are all required for the proliferation of hematopoietic progenitors. However, during GATA-1-mediated activation of the $\beta$-globin gene, the HDAC1/NuRD/MeCP1 complex is still recruited to the GATA-1 sites of the $\beta$-globin locus. (3) HDACs act as multifunctional regulators of transcription complex activity. For instance, HDAC1 can be acetylated by histone acetyltransferase p300. Acetylated HDAC1 not only loses its deacetylase activity but also inhibits the deacetylase activity of HDAC2, thereby downregulating the overall 
deacetylase activity of $\mathrm{HDAC} 1 / 2$-containing complexes, including the NuRD complex.

Epigenetic changes that occur during the development of hematopoietic malignancies are reversible and amenable to pharmacological intervention. The abnormal activity and expression of HDACs or the occurrence of aberrant composition in HDAC-containing transcriptional complexes could lead to malignant hematopoiesis via hyperproliferation and/or blocks in differentiation. However, the molecular basis for hematopoietic transformation, malignant development and drug resistance by HDACs are still largely unclear. For example, although it has been found that the activity of HDACs is regulated through posttranslational modifications, i.e., $\mathrm{CBP} / \mathrm{p} 300$, and HDAC1 gene expression is regulated by the C/EBP family, GATA1 and Sp1, the misregulation in HDAC expression by multiple layers of regulation mechanisms, such as a given mutation or epigenetic modifier, are largely unknown. In some cases, the function of oncogenic TFs and fusion proteins is reliant on direct interactions with HDAC-containing complexes. For example, transcriptional and differential repression of several transcriptional fusion proteins with key roles in the progression of acute leukemias, such as AML1/ETO, STAT5/RARa, and PLZF/RARa fusion proteins, is mediated by the aberrant recruitment of corepressor complexes in the $\mathrm{N}-\mathrm{CoR} / \mathrm{mSin} 3 / \mathrm{HDAC} 1$ complex. Hence, many HDAC-TF/cofactor interaction surfaces represent compelling therapeutic targets.

In hematopoietic systems, HDACis have shown synergistic or additive effects with numerous chemotherapeutic agents, such as proteasome inhibitors, hormonal therapy, tyrosine kinase inhibitors, DNAhypomethylating agents, and immune checkpoint inhibitors, in preclinical and clinical settings. HDACis recently emerged as promising immunomodulatory drugs, like TMP195 and ACY241, via modulation of immune cell phenotypes or expression of immune checkpoints [80, 172]. Immune checkpoint inhibitors have revolutionized the treatment of hematological malignancies. Their combination with HDACis may be considered a major breakthrough in the treatment of hematological malignancies. Furthermore, more current research efforts are focused on developing HDAC isoform-selective inhibitors to improve toxicity against specific cancer types and overcome drug resistance or off-target effects. The availability of crystal structures of HDAC isoforms may provide a major contribution to understanding isoform selectivity.

Given that epigenetic regulation of HDACs globally affects the gene regulatory network, an ensemble of key hematopoietic HDACs has been identified. Future studies need to identify more regulatory factors that dysregulate HDAC expression and determine how their misexpression contributes to the pathogenesis of hematological malignancies. Identification of more structures of HDAC isoforms and epigenetic mechanisms, thereby targeting specific HDAC, HDAC pathways and HDAC-TF/cofactor interactions may represent ideal strategies to treat malignant hematopoiesis.

\begin{abstract}
Abbreviations
ALL: Acute lymphocytic leukemia; ALPs: All-lymphoid progenitors; AML MLL: Acute myeloid leukemia with a Mixed Lineage Leukemia; AML: Acute myeloid leukemia; APCs: Antigen-presenting cells; APL: Acute promyelocytic leukemia; BFU-E: Burst-forming unit-erythroid; BLPs: B cell-biased lymphoid progenitors; BMDMs: Bone marrow-derived monocytes; B-NHL: B cell nonHodgkin lymphoma; CAR: Contractile actin ring; CFU-E: Colony-forming uniterythroid; CK2: Casein kinase 2; CKO: Conditional knockout; CLL: Chronic lymphocytic leukemia; CLP: Common lymphoid progenitor; CML: Chronic myeloid leukemia; CMP: Common myeloid progenitor; CRc: Composite complete response; CTCL: Cutaneous T-cell lymphoma; DCs: Dendritic cells; DLBCL: Diffuse large B cell lymphoma; DN: Double-negative; DP: Doublepositive; FL: Follicular lymphoma; GC: Germinal center; GCL: Glutamate cysteine ligase; GMCSFR: Granulocyte colony-stimulating factor; GMP: Granulocyte-monocyte progenitor; GSH: Glutathione; HAT: Histone acetyltransferase; HD: Hodgkin disease; HDACis: Histone deacetylase inhibitors; HDACs: Histone deacetylases; HL: Hodgkin's lymphoma; HPCs: Hematopoietic progenitor cells; HSC: Hematopoietic stem cell; ISP: Immature single-positive; LMPP: Lymphoid-primed multipotential progenitor; MCSFR: Granulocyte-macrophage colony-stimulating factor; MDS: Myelodysplastic syndrome; MEP: Megakaryocyte- erythrocyte progenitor; MLP: Multilineage progenitor; MM: Multiple myeloma; NHL: NonHodgkin lymphoma; ORR: Overall response rate; PlsEtn: Plasmalogens; RORyt: Retinoic acid-related orphan receptor; RTEs: Recent thymic emigrants; SOD: Superoxide dismutase; TCR: T cell receptor; TF: Transcription factor; Tregs: T regulatory cells
\end{abstract}

\section{Acknowledgements}

Not applicable.

\section{Authors' contributions}

ZW and PW designed this study. ZW and PW drafted the manuscript. JL, ZW and PW revised this manuscript. PW drew the figures. All authors read and approved the final manuscript.

\section{Funding}

This work was supported by the grants from National Key Research and Development Program of China (2108YFA0107800); National Natural Science Foundation of China [Grant numbers 81920108004, 81770107, 81470362 and 81702722]; National Postdoctoral Program for Innovative Talents [Grant number BX201700292]; Natural Science Foundation of Hunan Province [Grant number 2018JJ3703]; Science and Technology Key Project of Hunan Province [Grant number 2018SK21212]; Fundamental Research Funds for the Central Universities of Central South University [Grant number 2018zzts386].

\section{Availability of data and materials}

Not applicable.

Ethics approval and consent to participate

Not applicable.

Consent for publication

All of the authors are aware of and agree to the content of the paper and their being listed as a co-author of the paper.

Competing interests

The authors declare that they have no competing interests. 


\section{Received: 24 September 2019 Accepted: 26 December 2019}

\section{Published online: 07 January 2020}

\section{References}

1. Greco TM, Yu F, Guise AJ, Cristea IM. Nuclear import of histone deacetylase 5 by requisite nuclear localization signal phosphorylation. Mol Cell Proteomics. 2011;10:M110.004317.

2. Sahakian E, Chen J, Powers JJ, Chen X, Maharaj K, Deng SL, Achille AN, Lienlaf M, Wang HW, Cheng F, et al. Essential role for histone deacetylase 11 (HDAC11) in neutrophil biology. J Leukoc Biol. 2017;102:475-86.

3. Shah RR, Koniski A, Shinde M, Blythe SA, Fass DM, Haggarty SJ, Palis J, Klein PS. Regulation of primitive hematopoiesis by class I histone deacetylases. Dev Dyn. 2013;242:108-21.

4. Varricchio L, Dell'Aversana C, Nebbioso A, Migliaccio G, Altucci L, Mai A, Grazzini G, Bieker JJ, Migliaccio AR. Identification of NURSERY, a new functional HDAC complex composed by HDAC5, GATA1, EKLF and pERK present in human erythroid cells. Int J Biochem Cell Biol. 2014;50:112-22.

5. Watamoto K, Towatari M, Ozawa Y, Miyata Y, Okamoto M, Abe A, Naoe T, Saito $\mathrm{H}$. Altered interaction of HDAC5 with GATA-1 during MEL cell differentiation. Oncogene. 2003;22:9176-84.

6. Wada T, Kikuchi J, Nishimura N, Shimizu R, Kitamura T, Furukawa Y. Expression levels of histone deacetylases determine the cell fate of hematopoietic progenitors. J Biol Chem. 2009;284:30673-83.

7. Micelli C, Rastelli G. Histone deacetylases: structural determinants of inhibitor selectivity. Drug Discov Today. 2015;20:718-35.

8. Parra M, Verdin E. Regulatory signal transduction pathways for class lla histone deacetylases. Curr Opin Pharmacol. 2010;10:454-60.

9. Delehanty LL, Bullock GC, Goldfarb AN. Protein kinase D-HDAC5 signaling regulates erythropoiesis and contributes to erythropoietin cross-talk with GATA1. Blood. 2012:120:4219-28.

10. Yanginlar C, Logie C. HDAC11 is a regulator of diverse immune functions. Biochim Biophys Acta Gene Regul Mech. 1861;2018:54-9.

11. Prasad P, Ronnerblad M, Arner E, Itoh M, Kawaji H, Lassmann T, Daub CO, Forrest AR, Lennartsson A, Ekwall K. High-throughput transcription profiling identifies putative epigenetic regulators of hematopoiesis. Blood. 2014;123: e46-57.

12. Fujiwara $T$, Lee $H Y$, Sanalkumar $R$, Bresnick EH. Building multifunctionality into a complex containing master regulators of hematopoiesis. Proc Natl Acad Sci U S A. 2010;107:20429-34.

13. Chen GY, Osada H, Santamaria-Babi LF, Kannagi R. Interaction of GATA-3/Tbet transcription factors regulates expression of sialyl Lewis $X$ homing receptors on Th1/Th2 lymphocytes. Proc Natl Acad Sci U S A. 2006;103: 16894-9.

14. Duan Z, Zarebski A, Montoya-Durango D, Grimes HL, Horwitz M. Gfi coordinates epigenetic repression of p21Cip/WAF1 by recruitment of histone lysine methyltransferase G9a and histone deacetylase 1. Mol Cell Biol. 2005;25:10338-51.

15. Saleque S, Kim J, Rooke HM, Orkin SH. Epigenetic regulation of hematopoietic differentiation by Gfi- 1 and Gfi- $1 \mathrm{~b}$ is mediated by the cofactors CoREST and LSD1. Mol Cell. 2007;27:562-72.

16. van Oorschot $R$, Hansen M, Koornneef JM, Marneth AE, Bergevoet SM, van Bergen M, van Alphen FPJ, van der Zwaan C, Martens JHA, Vermeulen M, et al. Molecular mechanisms of bleeding disorderassociated GFI1B(Q287*) mutation and its affected pathways in megakaryocytes and platelets. Haematologica. 2019;104:1460-72.

17. Kong S, Kim SJ, Sandal B, Lee SM, Gao B, Zhang DD, Fang D. The type III histone deacetylase Sirt1 protein suppresses p300-mediated histone $\mathrm{H} 3$ lysine 56 acetylation at Bclaf1 promoter to inhibit T cell activation. J Biol Chem. 2011:286:16967-75.

18. Heideman MR, Lancini C, Proost N, Yanover E, Jacobs H, Dannenberg JH. Sin3a-associated Hdac1 and Hdac2 are essential for hematopoietic stem cell homeostasis and contribute differentially to hematopoiesis. Haematologica. 2014;99:1292-303.

19. Iwasaki H, Mizuno S, Arinobu Y, Ozawa H, Mori Y, Shigematsu H, Takatsu K, Tenen DG, Akashi K. The order of expression of transcription factors directs hierarchical specification of hematopoietic lineages. Genes Dev. 2006;20: 3010-21.

20. Yamamura K, Ohishi K, Katayama N, Yu Z, Kato K, Masuya M, Fujieda A Sugimoto Y, Miyata E, Shibasaki T, et al. Pleiotropic role of histone deacetylases in the regulation of human adult erythropoiesis. $\mathrm{Br} J$ Haematol. 2006;135:242-53.
21. Elizalde C, Fernandez-Rueda J, Salcedo JM, Dorronsoro A, Ferrin I, Jakobsson E, Trigueros C. Histone deacetylase 3 modulates the expansion of human hematopoietic stem cells. Stem Cells Dev. 2012;21:2581-91.

22. Summers $A R$, Fischer MA, Stengel $K R$, Zhao $Y$, Kaiser JF, Wells $C E$, Hunt $A$ Bhaskara S, Luzwick JW, Sampathi S, et al. HDAC3 is essential for DNA replication in hematopoietic progenitor cells. J Clin Invest. 2013;123:3112-23.

23. Wei Y, Ma D, Gao Y, Zhang C, Wang L, Liu F. Ncor2 is required for hematopoietic stem cell emergence by inhibiting Fos signaling in zebrafish. Blood. 2014;124:1578-85.

24. Ozawa Y, Towatari M, Tsuzuki S, Hayakawa F, Maeda T, Miyata Y, Tanimoto M, Saito $\mathrm{H}$. Histone deacetylase 3 associates with and represses the transcription factor GATA-2. Blood. 2001;98:2116-23.

25. Hua WK, Qi J, Cai Q, Carnahan E, Ayala Ramirez M, Li L, Marcucci G, Kuo YH. HDAC8 regulates long-term hematopoietic stem-cell maintenance under stress by modulating p53 activity. Blood. 2017;130:2619-30.

26. Huang X, Guo B, Liu S, Wan J, Broxmeyer HE. Neutralizing negative epigenetic regulation by HDAC5 enhances human haematopoietic stem cell homing and engraftment. Nat Commun. 2018;9:2741.

27. Roth $M$, Wang $Z$, Chen WY. Sirtuins in hematological aging and malignancy. Crit Rev Oncog. 2013;18:531-47.

28. Leko V, Varnum-Finney B, Li H, Gu Y, Flowers D, Nourigat C, Bernstein ID, Bedalov A. SIRT1 is dispensable for function of hematopoietic stem cells in adult mice. Blood. 2012;119:1856-60.

29. Rimmele P, Bigarella CL, Liang R, Izac B, Dieguez-Gonzalez R, Barbet G, Donovan M, Brugnara C, Blander JM, Sinclair DA, Ghaffari S. Aging-like phenotype and defective lineage specification in SIRT1-deleted hematopoietic stem and progenitor cells. Stem Cell Reports. 2014;3:44-59.

30. Brown K, Xie S, Qiu X, Mohrin M, Shin J, Liu Y, Zhang D, Scadden DT, Chen D. SIRT3 reverses aging-associated degeneration. Cell Rep. 2013;3:319-27.

31. Wang H, Diao D, Shi Z, Zhu X, Gao Y, Gao S, Liu X, Wu Y, Rudolph KL, Liu G, et al. SIRT6 controls hematopoietic stem cell homeostasis through epigenetic regulation of Wnt signaling. Cell Stem Cell. 2016;18:495-507.

32. Wrighton KH. Stem cells: SIRT7, the UPR and HSC ageing. Nat Rev Mol Cell Biol. 2015;16:266-7.

33. Wang Z, Yuan H, Roth M, Stark JM, Bhatia R, Chen WY. SIRT1 deacetylase promotes acquisition of genetic mutations for drug resistance in CML cells. Oncogene. 2013;32:589-98.

34. Borregaard N. Neutrophils, from marrow to microbes. Immunity. 2010;33: 657-70.

35. Das Gupta K, Shakespear MR, Iyer A, Fairlie DP, Sweet MJ. Histone deacetylases in monocyte/macrophage development, activation and metabolism: refining HDAC targets for inflammatory and infectious diseases. Clin Transl Immunology. 2016;5:e62.

36. Ostuni R, Natoli G, Cassatella MA, Tamassia N. Epigenetic regulation of neutrophil development and function. Semin Immunol. 2016;28:83-93.

37. Cabanel M, Brand C, Oliveira-Nunes MC, Cabral-Piccin MP, Lopes MF, Brito JM, de Oliveira FL, El-Cheikh MC, Carneiro K. Epigenetic control of macrophage shape transition towards an atypical elongated phenotype by histone Deacetylase activity. PLoS One. 2015;10:e0132984.

38. Wisnik E, Ploszaj T, Robaszkiewicz A. Author correction: Downregulation of PARP1 transcription by promoter-associated E2F4-RBL2-HDAC1-BRM complex contributes to repression of pluripotency stem cell factors in human monocytes. Sci Rep. 2018;8:5764.

39. Aude-Garcia C, Collin-Faure V, Bausinger H, Hanau D, Rabilloud T, Lemercier C. Dual roles for MEF2A and MEF2D during human macrophage terminal differentiation and c-Jun expression. Biochem J. 2010;430:237-44.

40. Leong WY, Guo H, Ma O, Huang H, Cantor AB, Friedman AD. Runx1 phosphorylation by Src increases trans-activation via augmented stability, reduced histone Deacetylase (HDAC) binding, and increased DNA affinity, and activated Runx1 favors Granulopoiesis. J Biol Chem. 2016;291:826-36.

41. Yang Q, Wei J, Zhong L, Shi M, Zhou P, Zuo S, Wu K, Zhu M, Huang X, Yu Y, et al. Cross talk between histone deacetylase 4 and STAT6 in the transcriptional regulation of arginase 1 during mouse dendritic cell differentiation. Mol Cell Biol. 2015;35:63-75.

42. Gelmetti V, Zhang J, Fanelli M, Minucci S, Pelicci PG, Lazar MA. Aberrant recruitment of the nuclear receptor corepressor-histone deacetylase complex by the acute myeloid leukemia fusion partner ETO. Mol Cell Biol. 1998;18:7185-91.

43. Hu Z, Gu X, Baraoidan K, Ibanez V, Sharma A, Kadkol S, Munker R, Ackerman S, Nucifora G, Saunthararajah Y. RUNX1 regulates corepressor interactions of PU.1. Blood. 2011;117:6498-508. 
44. Houot R, Kohrt H, Goldstein MJ, Levy R. Immunomodulating antibodies and drugs for the treatment of hematological malignancies. Cancer Metastasis Rev. 2011;30:97-109.

45. Hu J, Liu J, Xue F, Halverson G, Reid M, Guo A, Chen L, Raza A, Galili N, Jaffray J, et al. Isolation and functional characterization of human erythroblasts at distinct stages: implications for understanding of normal and disordered erythropoiesis in vivo. Blood. 2013;121:3246-53.

46. Jian W, Yan B, Huang S, Qiu Y. Histone deacetylase 1 activates PU.1 gene transcription through regulating TAF9 deacetylation and transcription factor IID assembly. FASEB J. 2017;31:4104-16.

47. Ahringer J. NuRD and SIN3 histone deacetylase complexes in development. Trends Genet. 2000;16:351-6.

48. Chen X, Bieker JJ. Stage-specific repression by the EKLF transcriptional activator. Mol Cell Biol. 2004;24:10416-24.

49. Suzuki M, Yamada T, Kihara-Negishi F, Sakurai T, Oikawa T. Direct association between PU.1 and MeCP2 that recruits mSin3A-HDAC complex for PU.1mediated transcriptional repression. Oncogene. 2003;22:8688-98.

50. Gregory GD, Miccio A, Bersenev A, Wang Y, Hong W, Zhang Z, Poncz M, Tong W, Blobel GA. FOG1 requires NuRD to promote hematopoiesis and maintain lineage fidelity within the megakaryocytic-erythroid compartment. Blood. 2010;115:2156-66

51. Yang T, Jian W, Luo Y, Fu X, Noguchi C, Bungert J, Huang S, Qiu Y. Acetylation of histone deacetylase 1 regulates NuRD corepressor complex activity. J Biol Chem. 2012;287:40279-91

52. Yamamoto R, Kawahara M, Ito S, Satoh J, Tatsumi G, Hishizawa M, Suzuki T, Andoh A. Selective dissociation between LSD1 and GFI1B by a LSD1 inhibitor NCD38 induces the activation of ERG super-enhancer in erythroleukemia cells. Oncotarget. 2018;9:21007-21.

53. Bottardi S, Ross J, Bourgoin V, Fotouhi-Ardakani N, Affarel B, Trudel M, Milot E. Ikaros and GATA-1 combinatorial effect is required for silencing of human gamma-globin genes. Mol Cell Biol. 2009;29:1526-37.

54. Zhao Q, Cumming H, Cerruti L, Cunningham JM, Jane SM. Site-specific acetylation of the fetal globin activator NF-E4 prevents its ubiquitination and regulates its interaction with the histone deacetylase, HDAC1. J Biol Chem. 2004;279:41477-86.

55. Mankidy R, Faller DV, Mabaera R, Lowrey $\mathrm{CH}$, Boosalis MS, White GL, Castaneda SA, Perrine SP. Short-chain fatty acids induce gamma-globin gene expression by displacement of a HDAC3-NCoR repressor complex. Blood. 2006;108:3179-86.

56. Muralidhar SA, Ramakrishnan V, Kalra IS, Li W, Pace BS. Histone deacetylase 9 activates gamma-globin gene expression in primary erythroid cells. J Biol Chem. 2011;286:2343-53.

57. Ji P, Yeh V, Ramirez T, Murata-Hori M, Lodish HF. Histone deacetylase 2 is required for chromatin condensation and subsequent enucleation of cultured mouse fetal erythroblasts. Haematologica. 2010;95:2013-21.

58. Li X, Mei Y, Yan B, Vitriol E, Huang S, Ji P, Qiu Y. Histone deacetylase 6 regulates cytokinesis and erythrocyte enucleation through deacetylation of formin protein mDia2. Haematologica. 2017;102:984-94.

59. Cobaleda C, Busslinger M. Developmental plasticity of lymphocytes. Curr Opin Immunol. 2008;20:139-48.

60. Barneda-Zahonero B, Roman-Gonzalez L, Collazo O, Mahmoudi T, Parra M. Epigenetic regulation of $B$ lymphocyte differentiation, transdifferentiation, and reprogramming. Comp Funct Genomics. 2012;2012:564381.

61. Azagra A, Roman-Gonzalez L, Collazo O, Rodriguez-Ubreva J, de Yebenes VG, Barneda-Zahonero B, Rodriguez J, Castro de Moura M, Grego-Bessa J, Fernandez-Duran I, et al. in vivo conditional deletion of HDAC7 reveals its requirement to establish proper B lymphocyte identity and development. J Exp Med. 2016;213:2591-601.

62. Yamaguchi T, Cubizolles F, Zhang Y, Reichert N, Kohler H, Seiser C, Matthias P. Histone deacetylases 1 and 2 act in concert to promote the G1-to-S progression. Genes Dev. 2010;24:455-69.

63. Yu J, Angelin-Duclos C, Greenwood J, Liao J, Calame K. Transcriptional repression by blimp-1 (PRDI-BF1) involves recruitment of histone deacetylase. Mol Cell Biol. 2000;20:2592-603.

64. Ying HY, Su ST, Hsu PH, Chang CC, Lin IY, Tseng YH, Tsai MD, Shih HM, Lin KI. SUMOylation of Blimp-1 is critical for plasma cell differentiation. EMBO Rep. 2012;13:631-7.

65. Pillonel V, Reichert N, Cao C, Heideman MR, Yamaguchi T, Matthias G, Tzankov A, Matthias P. Histone deacetylase 1 plays a predominant pro-oncogenic role in emu-myc driven B cell lymphoma. Sci Rep. 2016;6:37772.
66. Wang H, Song C, Ding Y, Pan X, Ge Z, Tan BH, Gowda C, Sachdev M, Muthusami S, Ouyang $\mathrm{H}$, et al. Transcriptional regulation of JARID1B/KDM5B histone Demethylase by Ikaros, histone Deacetylase 1 (HDAC1), and casein kinase 2 (CK2) in B-cell acute lymphoblastic leukemia. J Biol Chem. 2016;291: 4004-18.

67. Song C, Pan X, Ge Z, Gowda C, Ding Y, Li H, Li Z, Yochum G, Muschen M, Li $Q$, et al. Epigenetic regulation of gene expression by Ikaros, HDAC1 and casein kinase II in leukemia. Leukemia. 2016;30:1436-40.

68. Huang C, Gonzalez DG, Cote CM, Jiang Y, Hatzi K, Teater M, Dai K, Hla T, Haberman AM, Melnick A. The BCL6 RD2 domain governs commitment of activated B cells to form germinal centers. Cell Rep. 2014;8:1497-508.

69. Stengel KR, Barnett KR, Wang J, Liu Q, Hodges E, Hiebert SW, Bhaskara S. Deacetylase activity of histone deacetylase 3 is required for productive VDJ recombination and B-cell development. Proc Natl Acad Sci U S A. 2017;114: 8608-13.

70. Nanou A, Toumpeki C, Lavigne MD, Lazou V, Demmers J, Paparountas T, Thanos D, Katsantoni E. The dual role of LSD1 and HDAC3 in STAT5dependent transcription is determined by protein interactions, binding affinities, motifs and genomic positions. Nucleic Acids Res. 2017;45:142-54.

71. Tanaka H, Muto A, Shima H, Katoh Y, Sax N, Tajima S, Brydun A, Ikura T, Yoshizawa N, Masai $H$, et al. Epigenetic regulation of the Blimp-1 gene (Prdm1) in B cells involves Bach2 and histone Deacetylase 3. J Biol Chem. 2016;291:6316-30.

72. Pasqualucci L, Dominguez-Sola D, Chiarenza A, Fabbri G, Grunn A, Trifonov $V$, Kasper LH, Lerach S, Tang H, Ma J, et al. Inactivating mutations of acetyltransferase genes in B-cell lymphoma. Nature. 2011;471:189-95.

73. Jiang Y, Ortega-Molina A, Geng H, Ying HY, Hatzi K, Parsa S, McNally D, Wang L, Doane AS, Agirre $X$, et al. CREBBP inactivation promotes the development of HDAC3-dependent lymphomas. Cancer Discov. 2017;7:38-53.

74. Gil VS, Bhagat G, Howell L, Zhang J, Kim CH, Stengel S, Vega F, Zelent A, Petrie K. Deregulated expression of HDAC9 in B cells promotes development of lymphoproliferative disease and lymphoma in mice. Dis Model Mech. 2016;9:1483-95.

75. Lemercier C, Brocard MP, Puvion-Dutilleul F, Kao HY, Albagli O, Khochbin S. Class II histone deacetylases are directly recruited by BCL6 transcriptional repressor. J Biol Chem. 2002;277:22045-52.

76. Sandhu SK, Volinia S, Costinean S, Galasso M, Neinast R, Santhanam R, Parthun MR, Perrotti D, Marcucci G, Garzon R. Croce CM: miR-155 targets histone deacetylase 4 (HDAC4) and impairs transcriptional activity of B-cell lymphoma 6 (BCL6) in the emu-miR-155 transgenic mouse model. Proc Natl Acad Sci U S A. 2012;109:20047-52.

77. Barneda-Zahonero B, Collazo O, Azagra A, Fernandez-Duran I, Serra-Musach J, Islam AB, Vega-Garcia N, Malatesta R, Camos M, Gomez A, et al. The transcriptional repressor HDAC7 promotes apoptosis and c-Myc downregulation in particular types of leukemia and lymphoma. Cell Death Dis. 2015;6:e1635.

78. Matthews SA, Liu P, Spitaler M, Olson EN, McKinsey TA, Cantrell DA, Scharenberg AM. Essential role for protein kinase D family kinases in the regulation of class II histone deacetylases in B lymphocytes. Mol Cell Biol. 2006;26:1569-77.

79. Powers JJ, Maharaj KK, Sahakian E, Xing L, PerezVillarroel P, Knox T, Quayle S, Jones SS, Villagra A, Sotomayor EM, Pinilla-lbarz J. Histone Deacetylase 6 (HDAC6) As a Regulator of Immune Check-Point Molecules in Chronic Lymphocytic Leukemia (CLL). Blood. 2014;124:3311.

80. Bae J, Hideshima T, Tai YT, Song Y, Richardson P, Raje N, Munshi NC, Anderson KC. Histone deacetylase (HDAC) inhibitor ACY241 enhances antitumor activities of antigen-specific central memory cytotoxic T lymphocytes against multiple myeloma and solid tumors. Leukemia. 2018;32:1932-47.

81. Tremblay-LeMay R, Rastgoo N, Chang H. Modulating PD-L1 expression in multiple myeloma: an alternative strategy to target the PD-1/PD-L1 pathway. J Hematol Oncol. 2018;11:46.

82. Terranova-Barberio M, Thomas S, Munster PN. Epigenetic modifiers in immunotherapy: a focus on checkpoint inhibitors. Immunotherapy. 2016;8:705-19.

83. Boucheron N, Tschismarov R, Goeschl L, Moser MA, Lagger S, Sakaguchi S, Winter M, Lenz F, Vitko D, Breitwieser FP, et al. CD4(+) T cell lineage integrity is controlled by the histone deacetylases HDAC1 and HDAC2. Nat Immunol. 2014;15:439-48.

84. Dovey OM, Foster CT, Conte N, Edwards SA, Edwards JM, Singh R, Vassiliou G, Bradley A, Cowley SM. Histone deacetylase 1 and 2 are essential for normal T-cell development and genomic stability in mice. Blood. 2013;121: $1335-44$. 
85. Philips RL, Lee JH, Gaonkar K, Chanana P, Chung JY, Romero Arocha SR, Schwab A, Ordog T, Shapiro VS. HDAC3 restrains CD8-lineage genes to maintain a bi-potential state in CD4(+)CD8(+) thymocytes for CD4-lineage commitment. Elife. 2019;8.

86. Philips RL, Chen MW, McWilliams DC, Belmonte PJ, Constans MM, Shapiro VS. HDAC3 is required for the Downregulation of RORgammat during Thymocyte positive selection. J Immunol. 2016;197:541-54.

87. Stengel KR, Zhao Y, Klus NJ, Kaiser JF, Gordy LE, Joyce S, Hiebert SW, Summers AR. Histone Deacetylase 3 is required for efficient T cell development. Mol Cell Biol. 2015;35:3854-65.

88. Hsu FC, Belmonte PJ, Constans MM, Chen MW, McWilliams DC, Hiebert SW, Shapiro VS. Histone Deacetylase 3 is required for T cell maturation. J Immunol. 2015;195:1578-90.

89. Wang L, Liu Y, Han R, Beier UH, Bhatti TR, Akimova T, Greene MI, Hiebert SW, Hancock WW. FOXP3+ regulatory T cell development and function require histone/protein deacetylase 3. J Clin Invest. 2015;125:1111-23.

90. Akimova T, Ge G, Golovina T, Mikheeva T, Wang L, Riley JL, Hancock WW. Histone/protein deacetylase inhibitors increase suppressive functions of human FOXP3+ Tregs. Clin Immunol. 2010;136:348-63.

91. Kasler HG, Young BD, Mottet D, Lim HW, Collins AM, Olson EN, Verdin E. Histone deacetylase 7 regulates cell survival and TCR signaling in CD4/CD8 double-positive thymocytes. J Immunol. 2011;186:4782-93.

92. Parra M, Kasler H, McKinsey TA, Olson EN, Verdin E. Protein kinase D1 phosphorylates HDAC7 and induces its nuclear export after T-cell receptor activation. J Biol Chem. 2005;280:13762-70.

93. Xiao H, Jiao J, Wang L, O'Brien S, Newick K, Wang LC, Falkensammer E, Liu Y, Han R, Kapoor V, et al. HDAC5 controls the functions of Foxp3(+) Tregulatory and CD8(+) T cells. Int J Cancer. 2016;138:2477-86.

94. Villagra A, Cheng F, Wang HW, Suarez I, Glozak M, Maurin M, Nguyen D, Wright KL, Atadja PW, Bhalla K, et al. The histone deacetylase HDAC11 regulates the expression of interleukin 10 and immune tolerance. Nat Immunol. 2009:10:92-100.

95. Cheng F, Lienlaf M, Perez-Villarroel P, Wang HW, Lee C, Woan K, Woods D, Knox T, Bergman J, Pinilla-lbarz J, et al. Divergent roles of histone deacetylase 6 (HDAC6) and histone deacetylase 11 (HDAC11) on the transcriptional regulation of IL10 in antigen presenting cells. Mol Immunol. 2014;60:44-53.

96. Hagelkruys A, Sawicka A, Rennmayr M, Seiser C. The biology of HDAC in cancer: the nuclear and epigenetic components. Handb Exp Pharmacol. 2011;206:13-37

97. New M, Olzscha H, La Thangue NB. HDAC inhibitor-based therapies: can we interpret the code? Mol Oncol. 2012;6:637-56.

98. Barneda-Zahonero B, Parra M. Histone deacetylases and cancer. Mol Oncol. 2012;6:579-89.

99. Wang J, Hoshino T, Redner RL, Kajigaya S, Liu JM. ETO, fusion partner in t (8; 21) acute myeloid leukemia, represses transcription by interaction with the human N-CoR/mSin3/HDAC1 complex. Proc Natl Acad Sci U S A. 1998;95: 10860-5.

100. Faroogi AA, Naqvi SK, Perk AA, Yanar O, Tabassum S, Ahmad MS, Mansoor Q, Ashry MS, Ismail M, Naoum GE, Arafat WO. Natural agents-mediated targeting of histone Deacetylases. Arch Immunol Ther Exp. 2018;66:31-44.

101. Fu L, Shi J, Liu A, Zhou L, Jiang M, Fu H, Xu K, Li D, Deng A, Zhang Q, et al. A minicircuitry of microRNA-9-1 and RUNX1-RUNX1T1 contributes to leukemogenesis in t (8;21) acute myeloid leukemia. Int J Cancer. 2017;140: 653-61.

102. Liu J, Lu W, Liu S, Wang Y, Li S, Xu Y, Xing H, Tang K, Tian Z, Rao Q, et al. ZFP36L2, a novel AML1 target gene, induces AML cells apoptosis and inhibits cell proliferation. Leuk Res. 2018;68:15-21.

103. Hoogeveen AT, Rossetti S, Stoyanova V, Schonkeren J, Fenaroli A, Schiaffonati L, van Unen L, Sacchi N. The transcriptional corepressor MTG16a contains a novel nucleolar targeting sequence deranged in t (16: 21)-positive myeloid malignancies. Oncogene. 2002;21:6703-12.

104. Stams WA, den Boer ML, Beverloo HB, Kazemier KM, van Wering ER, JankaSchaub GE, Pieters R. Effect of the histone deacetylase inhibitor depsipeptide on B-cell differentiation in both TEL-AML1-positive and negative childhood acute lymphoblastic leukemia. Haematologica. 2005;90: 1697-9.

105. Senyuk V, Chakraborty S, Mikhail FM, Zhao R, Chi Y, Nucifora G. The leukemia-associated transcription repressor AML1/MDS1/EVI1 requires CtBP to induce abnormal growth and differentiation of murine hematopoietic cells. Oncogene. 2002;21:3232-40.
106. Khan MM, Nomura T, Kim H, Kaul SC, Wadhwa R, Zhong S, Pandolfi PP, Ishii S. PML-RARalpha alleviates the transcriptional repression mediated by tumor suppressor Rb. J Biol Chem. 2001;276:43491-4.

107. Girard N, Tremblay M, Humbert M, Grondin B, Haman A, Labrecque J, Chen B, Chen Z, Chen SJ, Hoang T. RARalpha-PLZF oncogene inhibits C/EBPalpha function in myeloid cells. Proc Natl Acad Sci U S A. 2013;110:13522-7.

108. Boumber Y, Younes A, Garcia-Manero G. Mocetinostat (MGCD0103): a review of an isotype-specific histone deacetylase inhibitor. Expert Opin Investig Drugs. 2011;20:823-9.

109. Benedetti R, Conte M, Altucci L. Targeting histone Deacetylases in diseases: where are we? Antioxid Redox Signal. 2015;23:99-126.

110. Shen S, Kozikowski AP. Why Hydroxamates may not be the best histone Deacetylase inhibitors--what some may have forgotten or would rather forget? ChemMedChem. 2016;11:15-21.

111. Osko JD, Christianson DW. Methods for the expression, purification, and crystallization of histone deacetylase 6-inhibitor complexes. Methods Enzymol. 2019;626:447-74.

112. Chou CJ, Herman D, Gottesfeld JM. Pimelic diphenylamide 106 is a slow, tight-binding inhibitor of class I histone deacetylases. J Biol Chem. 2008;283: 35402-9.

113. Hu E, Chen Z, Fredrickson T, Zhu Y, Kirkpatrick R, Zhang GF, Johanson K, Sung CM, Liu R, Winkler J. Cloning and characterization of a novel human class I histone deacetylase that functions as a transcription repressor. J Biol Chem. 2000;275:15254-64.

114. Bieliauskas AV, Pflum MK. Isoform-selective histone deacetylase inhibitors. Chem Soc Rev. 2008;37:1402-13.

115. Saygin C, Carraway HE. Emerging therapies for acute myeloid leukemia. J Hematol Oncol. 2017;10:93.

116. Nanavati C, Mager DE. Sequential exposure of Bortezomib and Vorinostat is synergistic in multiple myeloma cells. Pharm Res. 2017;34:668-79.

117. Holkova B, Kmieciak M, Bose P, Yazbeck WY, Barr PM, Tombes MB, Shrader E, Weir-Wiggins C, Rollins AD, Cebula EM, et al. Phase 1 trial of carfilzomib (PR$171)$ in combination with vorinostat (SAHA) in patients with relapsed or refractory B-cell lymphomas. Leuk Lymphoma. 2016;57:635-43.

118. Xue K, Gu JJ, Zhang Q, Mavis C, Hernandez-llizaliturri FJ, Czuczman MS, Guo Y. Vorinostat, a histone deacetylase (HDAC) inhibitor, promotes cell cycle arrest and re-sensitizes rituximab- and chemo-resistant lymphoma cells to chemotherapy agents. J Cancer Res Clin Oncol. 2016;142:379-87.

119. Thompson RC, Vardinogiannis I, Gilmore TD. The sensitivity of diffuse large B-cell lymphoma cell lines to histone deacetylase inhibitor-induced apoptosis is modulated by BCL-2 family protein activity. PLoS One. 2013;8: e62822.

120. Zhou W, Zhu W, Ma L, Xiao F, Qian W. Proteasome inhibitor MG-132 enhances histone deacetylase inhibitor SAHA-induced cell death of chronic myeloid leukemia cells by an ROS-mediated mechanism and downregulation of the Bcr-Abl fusion protein. Oncol Lett. 2015;10:2899-904

121. Bu Q, Cui L, Li J, Du X, Zou W, Ding K, Pan J. SAHA and S116836, a novel tyrosine kinase inhibitor, synergistically induce apoptosis in imatinibresistant chronic myelogenous leukemia cells. Cancer Biol Ther. 2014;15: 951-62.

122. Dasmahapatra G, Patel H, Nguyen T, Attkisson E, Grant S. PLK1 inhibitors synergistically potentiate HDAC inhibitor lethality in imatinib mesylatesensitive or -resistant BCR/ABL+ leukemia cells in vitro and in vivo. Clin Cancer Res. 2013;19:404-14.

123. Nguyen $T$, Dai $Y$, Attkisson $E$, Kramer $L$, Jordan $N$, Nguyen $N$, Kolluri $N$, Muschen M, Grant S. HDAC inhibitors potentiate the activity of the $\mathrm{BCR} / \mathrm{ABL}$ kinase inhibitor $\mathrm{KW}-2449$ in imatinib-sensitive or -resistant BCR/ABL+ leukemia cells in vitro and in vivo. Clin Cancer Res. 2011;17: 3219-32.

124. Whitecross KF, Alsop AE, Cluse LA, Wiegmans A, Banks KM, Coomans C, Peart MJ, Newbold A, Lindemann RK, Johnstone RW. Defining the target specificity of ABT-737 and synergistic antitumor activities in combination with histone deacetylase inhibitors. Blood. 2009;113:1982-91.

125. Nieto $Y$, Valdez BC, Thall PF, Ahmed S, Jones RB, Hosing C, Popat U, Shpall EJ, Qazilbash M, Gulbis A, et al. Vorinostat combined with high-dose gemcitabine, Busulfan, and Melphalan with autologous stem cell transplantation in patients with refractory lymphomas. Biol Blood Marrow Transplant. 2015;21:1914-20.

126. Garcia-Manero G. Can we improve outcomes in patients with acute myelogenous leukemia? Incorporating HDAC inhibitors into front-line therapy. Best Pract Res Clin Haematol. 2012;25:427-35. 
127. Ding H, Peterson KL, Correia C, Koh B, Schneider PA, Nowakowski GS, Kaufmann SH. Histone deacetylase inhibitors interrupt HSP90*RASGRP1 and HSP90*CRAF interactions to upregulate BIM and circumvent drug resistance in lymphoma cells. Leukemia. 2017;31:1593-602.

128. Harousseau JL, Shaughnessy J Jr, Richardson P. Multiple myeloma. Hematology Am Soc Hematol Educ Program. 2004:237-56.

129. Gao L, Gao M, Yang G, Tao Y, Kong Y, Yang R, Meng X, Ai G, Wei R, Wu H, et al. Synergistic activity of Carfilzomib and Panobinostat in multiple myeloma cells via modulation of ROS generation and ERK1/2. Biomed Res Int. 2015;2015:459052.

130. Bottoni A, Rizzotto L, Lai TH, Liu C, Smith LL, Mantel R, Reiff S, El-Gamal D, Larkin K, Johnson AJ, et al. Targeting BTK through microRNA in chronic lymphocytic leukemia. Blood. 2016;128:3101-12.

131. Schwartz J, Niu X, Walton E, Hurley L, Lin H, Edwards H, Taub JW, Wang Z, Ge Y. Synergistic anti-leukemic interactions between ABT-199 and panobinostat in acute myeloid leukemia ex vivo. Am J Transl Res. 2016;8: 3893-902.

132. Matsuda Y, Yamauchi T, Hosono N, Uzui K, Negoro E, Morinaga K, Nishi R, Yoshida A, Kimura S, Maekawa T, Ueda T. Combination of panobinostat with ponatinib synergistically overcomes imatinib-resistant CML cells. Cancer Sci. 2016;107:1029-38.

133. Lemoine M, Derenzini E, Buglio D, Medeiros LJ, Davis RE, Zhang J, Ji Y, Younes A. The pan-deacetylase inhibitor panobinostat induces cell death and synergizes with everolimus in Hodgkin lymphoma cell lines. Blood. 2012;119:4017-25.

134. Mondello P, Brea EJ, De Stanchina E, Toska E, Chang AY, Fennell M, Seshan V, Garippa R, Scheinberg DA, Baselga J, et al. Panobinostat acts synergistically with ibrutinib in diffuse large B cell lymphoma cells with MyD88 L265P mutations. JCI Insight. 2017;2:e90196.

135. Chu Y, Yahr A, Huang B, Ayello J, Barth M. M SC: Romidepsin alone or in combination with anti-CD20 chimeric antigen receptor expanded natural killer cells targeting Burkitt lymphoma in vitro and in immunodeficient mice. Oncoimmunology. 2017;6:e1341031.

136. Yan B, Chen Q, Shimada K, Tang M, Li H, Gurumurthy A, Khoury JD, Xu B, Huang S, Qiu Y. Histone deacetylase inhibitor targets CD123/CD47-positive cells and reverse chemoresistance phenotype in acute myeloid leukemia. Leukemia. 2019;33:931-44.

137. Tabe $Y$, Konopleva M, Contractor R, Munsell M, Schober WD, Jin L, TsutsumiIshii Y, Nagaoka I, Igari J, Andreeff M. Up-regulation of MDR1 and induction of doxorubicin resistance by histone deacetylase inhibitor depsipeptide (FK228) and ATRA in acute promyelocytic leukemia cells. Blood. 2006;107: 1546-54.

138. O'Connor OA, Ozcan M, Jacobsen ED, Roncero JM, Trotman J, Demeter J, Masszi T, Pereira J, Ramchandren R, Beaven A, et al. Randomized phase III study of Alisertib or Investigator's choice (selected single agent) in patients with relapsed or refractory peripheral T-cell lymphoma. J Clin Oncol. 2019; 37:613-23.

139. Reiman T, Savage K, Crump M, Cheung MC, MacDonald D, Buckstein R, Couban S, Piliotis E, Imrie K, Spaner D, et al. A phase I study of romidepsin, gemcitabine, dexamethasone and cisplatin combination therapy in the treatment of peripheral T-cell and diffuse large B-cell lymphoma; the Canadian cancer trials group LY.15 studydagger. Leuk Lymphoma. 2019;60: 912-9.

140. Amengual JE, Lichtenstein R, Lue J, Sawas A, Deng C, Lichtenstein E, Khan K, Atkins L, Rada A, Kim HA, et al. A phase 1 study of romidepsin and pralatrexate reveals marked activity in relapsed and refractory T-cell lymphoma. Blood. 2018;131:397-407.

141. Havas AP, Rodrigues KB, Bhakta A, Demirjian JA, Hahn S, Tran J, Scavello M, Tula-Sanchez AA, Zeng Y, Schmelz M, Smith CL. Belinostat and vincristine demonstrate mutually synergistic cytotoxicity associated with mitotic arrest and inhibition of polyploidy in a preclinical model of aggressive diffuse large B cell lymphoma. Cancer Biol Ther. 2016;17:1240-52.

142. Dai $Y$, Chen S, Wang L, Pei XY, Kramer LB, Dent P, Grant S. Bortezomib interacts synergistically with belinostat in human acute myeloid leukaemia and acute lymphoblastic leukaemia cells in association with perturbations in NF-kappaB and Bim. Br J Haematol. 2011;153:222-35.

143. Ngamphaiboon N, Dy GK, Ma WW, Zhao Y, Reungwetwattana T, DePaolo D, Ding Y, Brady W, Fetterly G, Adjei AA. A phase I study of the histone deacetylase (HDAC) inhibitor entinostat, in combination with sorafenib in patients with advanced solid tumors. Investig New Drugs. 2015;33:225-32.
144. Suraweera A, O'Byrne KJ, Richard DJ. Combination therapy with histone Deacetylase inhibitors (HDACi) for the treatment of Cancer: achieving the full therapeutic potential of HDACi. Front Oncol. 2018; 8:92.

145. lacomino G, Medici MC, Russo GL. Valproic acid sensitizes K562 erythroleukemia cells to TRAIL/Apo2L-induced apoptosis. Anticancer Res. 2008;28:855-64

146. Davood ZA, Shamsi S, Ghaedi H, Sahand RI, Mojtaba G, Mahdi T, Reza M, Ebrahimi MJ, Miri-Moosavi RS, Boosaliki S, Davood OM. Valproic acid may exerts its cytotoxic effect through rassf1a expression induction in acute myeloid leukemia. Tumour Biol. 2016;37:11001-6.

147. Zhao J, Xie C, Edwards H, Wang G, Taub JW, Ge Y. Histone deacetylases 1 and 2 cooperate in regulating BRCA1, CHK1, and RAD51 expression in acute myeloid leukemia cells. Oncotarget. 2017;8:6319-29.

148. von Tresckow B, Diehl V. An update on emerging drugs for Hodgkin lymphoma. Expert Opin Emerg Drugs. 2014;19:215-24.

149. Liu HB, Mayes PA, Perlmutter P, McKendrick JJ, Dear AE. The antileukemic effect and molecular mechanisms of novel hydroxamate and benzamide histone deacetylase inhibitors with 5-aza-cytidine. Int J Oncol. 2011;38:1421-5.

150. Favreau AJ, McGlauflin RE, Duarte CW. Sathyanarayana P: miR-199b, a novel tumor suppressor miRNA in acute myeloid leukemia with prognostic implications. Exp Hematol Oncol. 2015;5:4.

151. Canella A, Cordero Nieves H, Sborov DW, Cascione L, Radomska HS, Smith E, Stiff A, Consiglio J, Caserta E, Rizzotto L, et al. HDAC inhibitor AR-42 decreases CD44 expression and sensitizes myeloma cells to lenalidomide. Oncotarget. 2015:6:31134-50.

152. Chen S, Zhang Y, Zhou L, Leng Y, Lin H, Kmieciak M, Pei XY, Jones R, Orlowski RZ, Dai Y, Grant S. A Bim-targeting strategy overcomes adaptive bortezomib resistance in myeloma through a novel link between autophagy and apoptosis. Blood. 2014;124:2687-97.

153. Jin Y, Yao Y, Chen L, Zhu X, Jin B, Shen Y, Li J, Du X, Lu Y, Jiang S, Pan J. Depletion of gamma-catenin by histone Deacetylase inhibition confers elimination of CML stem cells in combination with Imatinib. Theranostics. 2016;6:1947-62.

154. Zhang QL, Wang L, Zhang YW, Jiang XX, Yang F, Wu WL, Janin A, Chen Z Shen ZX, Chen SJ, Zhao WL. The proteasome inhibitor bortezomib interacts synergistically with the histone deacetylase inhibitor suberoylanilide hydroxamic acid to induce T-leukemia/lymphoma cells apoptosis. Leukemia. 2009;23:1507-14.

155. Mihailidou C, Papavassiliou AG, Kiaris H. Cell-autonomous cytotoxicity of type I interferon response via induction of endoplasmic reticulum stress. FASEB J. 2017:31:5432-9.

156. Rudek MA, Zhao M, He P, Hartke C, Gilbert J, Gore SD, Carducci MA, Baker SD. Pharmacokinetics of 5-azacitidine administered with phenylbutyrate in patients with refractory solid tumors or hematologic malignancies. J Clin Oncol. 2005:23:3906-11.

157. Cerchietti LC, Hatzi K, Caldas-Lopes E, Yang SN, Figueroa ME, Morin RD, Hirst M, Mendez L, Shaknovich R, Cole PA, et al. BCL6 repression of EP300 in human diffuse large $B$ cell lymphoma cells provides a basis for rational combinatorial therapy. J Clin Invest. 2010;120:4569-82.

158. Voorhees PM, Gasparetto C, Moore DT, Winans D, Orlowski RZ, Hurd DD. Final results of a phase 1 study of Vorinostat, Pegylated liposomal doxorubicin, and Bortezomib in relapsed or refractory multiple myeloma. Clin Lymphoma Myeloma Leuk. 2017;17:424-32.

159. Hauswald S, Duque-Afonso J, Wagner MM, Schertl FM, Lubbert M, Peschel C, Keller U, Licht T. Histone deacetylase inhibitors induce a very broad, pleiotropic anticancer drug resistance phenotype in acute myeloid leukemia cells by modulation of multiple ABC transporter genes. Clin Cancer Res. 2009;15:3705-15.

160. Fujii K, Suzuki N, Jimura N, Idogawa M, Kondo T, Iwatsuki K, Kanekura T. HSP72 functionally inhibits the anti-neoplastic effects of HDAC inhibitors. J Dermatol Sci. 2018;90:82-9.

161. Dahabieh MS, Ha Z, Di Pietro E, Nichol JN, Bolt AM, Goncalves C, DupereRicher D, Pettersson F, Mann KK, Braverman NE, et al. Peroxisomes protect lymphoma cells from HDAC inhibitor-mediated apoptosis. Cell Death Differ. 2017;24:1912-24.

162. Fujii K, Suzuki N, Ikeda K, Hamada T, Yamamoto T, Kondo T, Iwatsuki K. Proteomic study identified HSP $70 \mathrm{kDa}$ protein $1 \mathrm{~A}$ as a possible therapeutic target, in combination with histone deacetylase inhibitors, for lymphoid neoplasms. J Proteome. 2012;75:1401-10. 
163. Forthun RB, Sengupta T, Skjeldam HK, Lindvall JM, McCormack E, Gjertsen $\mathrm{BT}$, Nilsen $\mathrm{H}$. Cross-species functional genomic analysis identifies resistance genes of the histone deacetylase inhibitor valproic acid. PLoS One. 2012;7: e48992.

164. Fantin VR, Loboda A, Paweletz CP, Hendrickson RC, Pierce JW, Roth JA, Li L, Gooden F, Korenchuk S, Hou XS, et al. Constitutive activation of signal transducers and activators of transcription predicts vorinostat resistance in cutaneous T-cell lymphoma. Cancer Res. 2008;68:3785-94.

165. Huang R, Zhang X, Min Z, Shadia AS, Yang S, Liu X. MGCD0103 induces apoptosis and simultaneously increases the expression of NF-kappaB and PD-L1 in classical Hodgkin's lymphoma. Exp Ther Med. 2018;16:3827-34.

166. Liu H, Hu Y, Rimoldi R, Von Hagt C, Khong EWC, Lee N, Flemming S, Spencer A, Dear AE. Epigenetic treatment-mediated modulation of PD-L1 predicts potential therapy resistance over response markers in myeloid malignancies: a molecular mechanism involving effectors of PD-L1 reverse signaling. Oncol Lett. 2019;17:2543-50.

167. Noack K, Mahendrarajah N, Hennig D, Schmidt L, Grebien F, Hildebrand D, Christmann M, Kaina B, Sellmer A, Mahboobi S, et al. Analysis of the interplay between all-trans retinoic acid and histone deacetylase inhibitors in leukemic cells. Arch Toxicol. 2017;91:2191-208.

168. Peart MJ, Smyth GK, van Laar RK, Bowtell DD, Richon VM, Marks PA, Holloway AJ, Johnstone RW. Identification and functional significance of genes regulated by structurally different histone deacetylase inhibitors. Proc Natl Acad Sci U S A. 2005;102:3697-702.

169. Hu Y, Lu W, Chen G, Zhang H, Jia Y, Wei Y, Yang H, Zhang W, Fiskus W, Bhalla $\mathrm{K}$, et al. Overcoming resistance to histone deacetylase inhibitors in human leukemia with the redox modulating compound beta-phenylethyl isothiocyanate. Blood. 2010;116:2732-41.

170. Garcia-Manero G, Yang H, Bueso-Ramos C, Ferrajoli A, Cortes J, Wierda WG, Faderl S, Koller C, Morris G, Rosner G, et al. Phase 1 study of the histone deacetylase inhibitor vorinostat (suberoylanilide hydroxamic acid [SAHA]) in patients with advanced leukemias and myelodysplastic syndromes. Blood. 2008;111:1060-6.

171. Dupere-Richer D, Kinal M, Menasche V, Nielsen TH, Del Rincon S, Pettersson F. Miller WH Jr. Vorinostat-induced autophagy switches from a deathpromoting to a cytoprotective signal to drive acquired resistance. Cell Death Dis. 2013:4:e486.

172. Guerriero JL, Sotayo A, Ponichtera HE, Castrillon JA, Pourzia AL, Schad S, Johnson SF, Carrasco RD, Lazo S, Bronson RT, et al. Class Ila HDAC inhibition reduces breast tumours and metastases through anti-tumour macrophages. Nature. 2017;543:428-32.

\section{Publisher's Note}

Springer Nature remains neutral with regard to jurisdictional claims in published maps and institutional affiliations.

Ready to submit your research? Choose BMC and benefit from:

- fast, convenient online submission

- thorough peer review by experienced researchers in your field

- rapid publication on acceptance

- support for research data, including large and complex data types

- gold Open Access which fosters wider collaboration and increased citations

- maximum visibility for your research: over $100 \mathrm{M}$ website views per year

At $\mathrm{BMC}$, research is always in progress.

Learn more biomedcentral.com/submissions 